\title{
The Hybrid Invasive Weed Optimization-Shuffled Frog-leaping Algorithm Applied to Optimal Design of Frame Structures
}

\author{
Ali Kaveh ${ }^{1 *}$, Siamak Talatahari², Nima Khodadadi ${ }^{1}$ \\ ${ }^{1}$ Centre of Excellence for Fundamental Studies in Structural Engineering, \\ Iran University of Science and Technology, Narmak, Tehran, Iran \\ 2 Department of Civil Engineering, University of Tabriz, Tabriz, Iran \\ *Corresponding author, e-mail: alikaveh@iust.ac.ir
}

Received: 21 June 2019, Accepted: 14 July 2019, Published online: 22 August 2019

\begin{abstract}
In this article, an efficient hybrid optimization algorithm based on invasive weed optimization algorithm and shuffled frog-leaping algorithm is utilized for optimum design of skeletal frame structures. The shuffled frog-leaping algorithm is a population-based cooperative search metaphor inspired by natural memetic, and the invasive weed optimization algorithm is an optimization method based on dynamic growth of weeds colony. In the proposed algorithm, shuffled frog-leaping algorithm works to find optimal solution region rapidly, and invasive weed optimization performs the global search. Different benchmark frame structures are optimized using the new hybrid algorithm. Three design examples are tested using the new method. This algorithm converges to better or at least the same solutions compared the utilized methods with a smaller number of analyses. The outcomes are compared to those obtained previously using other recently developed meta-heuristic optimization methods.
\end{abstract}

Keywords

invasive weed optimization (IWO), shuffled frog-leaping algorithm (SFLA), hybrid (SELA-IWO) algorithm, optimal design, frame structures

\section{Introduction}

Structural optimization is the act of design and developing structures to provide the maximum profit of available resources. This topic has attracted a great deal of interest amongst scholars and has become a challenging and critical research subject in the last 30 years.

The optimization of frames is a challenging problem in engineering design that has been studied for the past decades, with different strategies and algorithms being tailored and used $[1,2]$. The intention of frame design optimization is to minimize the weight and cost of frames by means of selecting the suitable sections satisfying the strength and drift constraints of the utilized building code as well as other practical constraints such as constructability.

Meta-heuristic algorithms which can be used for discrete variable spaces, utilize randomness and memory to look for a large number of discrete variable spaces if one wants to locate the most appropriate solution. There have been an increasing tendency towards application of meta-heuristic search techniques [3], including genetic algorithms [4], harmony search method [5], particle swarm optimization [6], ant colony optimization [7], charged system search [8], ray optimization [9], big bang - big crunch [10], and water evaporation optimization [11] in tackling real-global structural optimization times. Generally, the primary intention in meta-heuristic based optimization techniques is to locate optimum solutions via investigating a portion of the solution space in an achievable computational time.

For frame structures the big bang-big crunch (BBBC) optimization algorithm was applied to optimum layout optimization of skeletal structures, Camp [12]. Kaveh and Abbasgholiha [13] utilized the BB-BC algorithm for optimal design of planar steel sway frames. For developing new efficient algorithms, many researchers tried to reduce searching time and enhanced the quality of the final optimal solution. They combine the strengths of different standard optimization algorithms in order to produce hybrid algorithms which are capable of searching for better solutions. For example, Kaveh and Talatahari [14] suggested hybrid versions of the BB-BC algorithm for design optimization of various classes of skeletal structures. Some efficient metaheuristics are applied to frame optimization in $[15,16]$. Recently, Kazemzadeh Azad et al. [17, 18] studied the performance of the BB-BC 
algorithm for solving engineering optimization problems. Kaveh and Malakoutirad [19] proposed a hybrid algorithm that combined the genetic algorithm with particle swarm optimization. Juang [20] suggested a hybridized GA and PSO, which together mimic social behaviors of animals, breeding, and survival of the fittest. Kaveh and Talatahari [21] proposed hybrid PSO-based methods combining particle swarm algorithm with concepts from ant colony optimization algorithm, PSACO and HPSACO. This method utilizes a particle swarm optimization with a passive congregation algorithm as a global search, and the idea of ant colony approach worked as a local search. The harmony search-based mechanism is used to handle the variable constraints.

Shuffled frog-leaping algorithm (SFLA) was developed by Eusuff et al. [22]. The algorithm contains elements of local search and global information exchange. The SFLA consists of a set of interacting virtual population of frogs partitioned into different memeplexes. To ensure global exploration, the virtual frogs are periodically shuffled and reorganized into new memplexes in a method similar to that used in the shuffled complex evolution algorithm. Additionally, to provide the chance for random generation of improved information, random virtual frogs are generated and entered into the population. Invasive weed optimization (IWO) was developed by Mehrabian and Lucas [23]. IWO is a nature inspired algorithm which has obtained more attention because it shows efficient exploration and dissimilarity properties and takes an exceptional place for solving continuous optimization problems. In standard IWO, the seeds are uniformly spread on the search space, Mehrabian and Lucas [23]. Hybrid algorithms have been developed by combining two or more algorithms to improve or enhance the overall search efficiency. An efficient hybrid optimization algorithm based on invasive weed optimization algorithm and shuffled frog-leaping algorithm is recently developed for optimum design of trusses. The shuffled frog-leaping algorithm is a population-based cooperative search metaphor inspired by natural memetic, and the invasive weed optimization algorithm is an optimization method based on dynamic growth of weeds colony, Kaveh et al. [24].

In the present work, the above-mentioned hybrid algorithm is utilized for optimal design of several frame structures with continues variables and the results are compared to those obtained by some other meta-heuristic algorithms.
The remainder of this paper is prepared as follows: Section 2 describes the optimum design problem of steel frames based on AISC provisions [25]. The SFLA-IWO algorithm is introduced in Section 3. Section 4 consists of three steel frames structures. The final section concludes the paper.

\section{Optimal layout of steel frames using AISC-LRFD}

In practical applications, frame members are chosen from set of existing steel sections which yields a discrete sizing optimization problem. In this research, the optimal design of frame structures are formulated as

$$
\begin{array}{ll}
\text { find } & X=\left[x_{1}, x_{2}, \ldots, x_{n}\right] \\
\text { to Minimize } & f i t(X)=W(X) \times f_{\text {penalty }}(X),
\end{array}
$$

where $X$ is the vector of design variables containing the cross-sectional areas of $W$ sections; $n$ is the number of design variables or the number of member groups; fit $(X)$ is the fitness function; $W(X)$ is the cost function which is usually taken as the weight or volume of the structure; $f_{\text {penalty }}(X)$ is the penalty function which results from Iviolations of the constraints corresponding to the response of the structure. The cost function in the form of the weight of frame structure is expressed as

$$
W(X)=\sum_{k=1}^{n} \rho_{i} \cdot A_{i} \cdot L_{i}
$$

where $\rho_{i}$ is the unit weight of the steel section, $A_{i}$ and $L_{i}$ are the cross and the length of the steel section. Here, the objective of finding the minimum cost of structure is subjected to several design constraints, including strength and serviceability requirements. According to AISC [25] for design, the following design constraints $\left(C_{I E L}^{i}\right.$ and $\left.C_{I E L}^{v}\right)$ should to be satisfied for the strength necessity.

$$
\begin{aligned}
& C_{I E L}^{i}=\left[\frac{P_{u J}}{\phi P_{n}}\right]_{I E L}+\frac{8}{9}\left(\frac{M_{u x J}}{\phi_{b} M_{n x}}+\frac{M_{u y J}}{\phi_{b} M_{n y}}\right)_{I E L}-1 \leq 0 \\
& \text { for }\left[\frac{P_{u J}}{\phi P_{n}}\right]_{I E L} \geq 0.2, \\
& C_{I E L}^{i}=\left[\frac{P_{u J}}{2 \phi P_{n}}\right]_{I E L}+\left(\frac{M_{u x J}}{\phi_{b} M_{n x}}+\frac{M_{u y J}}{\phi_{b} M_{n y}}\right)_{I E L}-1 \leq 0 \\
& \text { for } \quad\left[\frac{P_{u J}}{\phi P_{n}}\right]_{I E L}<0.2, \\
& C_{I E L}^{i}=\left(V_{u j}\right)_{I E L}-\left(\phi_{v} V_{n}\right) \leq 0 .
\end{aligned}
$$


In Eqs. (3-5), $I E L=1,2, \ldots, N E L$ is the element number, $N E L$ is the number of elements $j=1,2, \ldots, N$ is the load combination number and $N$ is the number of layout load combinations. $P_{u j}$ is the required axial (tensile or compressive) strength, under $j$ th layout load combination. $M_{u x j}$ and $M_{u y j}$ are the required flexural strengths for bending about $x$ and $y$, under the $j$ th layout load combination, respectively; where subscripts $x$ and $y$ are the relating symbols for strong and weak axes bending, respectively. Then again, $P_{n}, M_{n x}$ and $M_{n y}$ are the nominal axial (tensile or compressive) and flexural (for bending about $x$ and $y$ axes) strengths of the IELth member under evaluation (for two-dimensional structures $M_{n y}=0$ ). $\phi$, is the resistance factor for axial strength, which is 0.9 for compression and 0.85 for tension (based on yielding in the gross section) and $\phi_{b}$ is the resistance factor for flexure, which is equal to. Here, Eq. (5) is used for checking members' shear capacity wherein $V_{u j}$ is the required shear strength under $j$ th load combination and $V_{n}$ is the nominal shear strength of the IELth member under evaluation. In order to calculate the design shear strength, the nominal shear strength is multiplied by a resistance factor $\phi_{b}$ of 0.9 .

Further to the strength necessities, the serviceability constraints should be evaluated in the design process. The serviceability criteria $\left(C_{D}^{t}\right.$ and $\left.C_{F}^{d}\right)$ considered in this research are formulated as follows:

$C_{D}^{t}=\Delta_{\text {MaxJ }}-\Delta_{\text {Max }}^{a} \leq 0$,

$C_{F}^{d}=\left[\delta_{J}\right]_{F}-\left[\delta^{a}\right]_{F} \leq 0$.

Eq. (6) compares the maximum lateral displacement of the structure in the $D$ th direction $(D=1, \ldots, N D)$ under $j$ th load combination $\Delta_{\text {MaxJ }}$ with the maximum allowable lateral displacement $\Delta_{M a x}^{a}$. Likewise, Eq. (7) checks the interstory drift of the fifth story $(F=1,2, \ldots, N F)$ under the $j$ th load combination $\left[\delta_{J}\right]_{S}$ against the associated authorized value $\left[\delta^{a}\right]_{s}$; here $N F$ is the number of stories.

The penalty function is defined as [26]:

$$
f_{\text {penalty }}(X)=\left(1+\varepsilon_{1} \cdot v\right)^{\varepsilon_{2}} \quad v=\sum_{i=1}^{N G} \max \left[0, v_{i}\right],
$$

where $N G=N E L+N F+1$ represents the number of evaluated constraints for each individual design. Here, $N E L$ is the number of elements to control the interaction formula constraints (Eqs. (5) and (6)), $N F$ is the number of stories to check the inter-story drift constraint (Eq. (4)) and one is because of checking the total lateral displacement constraint. $\varepsilon_{1}$ is set to $1, \varepsilon_{2}$ is selected in a manner to decrease the penalties and reduce the cross-sectional areas. Thus, in the first steps of the search process, $\varepsilon_{2}$ is set to 1.5 and it is ultimately increased to 3 .

\subsection{Effective length factor $K$}

In order to compute the nominal compressive strength, the effective length factor $K$ must be determined for every member. This factor can be calculated using the frame buckling monograph introduced by Jackson and Moreland (see McGuire [27]). For sway frames, the effective length factor for columns is calculated as follows:

$\frac{\alpha^{2} G_{i} G_{j}-36}{6\left(G_{i}+G j\right)}=\frac{\alpha}{\tan \alpha}$,

$G_{i}=\frac{\sum I_{c i} / l_{c i}}{\sum I_{b i} / l_{b i}}, \quad G_{j}=\frac{\sum I_{c j} / l_{c j}}{\sum I_{b j} / l_{b j}}$,

where $\alpha=\pi / K, i$ and $j$ subscripts correspond to end $-i$ and end $-j$ of the compression member, and subscripts $c$ and $b$, in building structures, refer to columns and beams connecting to the joint under consideration, respectively. Parameters $I$ and $l$ in the above equations, represent the moment of inertia and unbraced length of the member, respectively. Here, $K$ factor for beam, bracings and nonsway column elements is taken as.

\section{Hybrid SFLA-IWO algorithm}

In order to make the paper self-explanatory, before introducing the SFLA-IWO algorithm for frame design optimization, the features of the SFLA and the IWO are briefly presented in the following two subsections. Then, the utilized hybrid method is presented [24].

\subsection{Shuffled Frog-Leaping Algorithm}

This algorithm is a meta-heuristic optimization technique which mimics the memetic evolution of a group of frogs when trying to find the location that has the maximum amount of available food. This algorithm involves elements of local search and global information exchange. The SFLA contains a population of possible solutions defined by a group of virtual frogs that are divided into subsets referred to as memeplexes. Within each memeplex, the individual frog holds ideas which get influenced by the ideas of other frogs, and therefore the concepts get evolved through a process of memetic evolution. The SFLA performs simultaneously an independent local search in each memeplex employing a particle swarm optimization-like method. In order to grantee the global exploration, after 
a defined number of memeplex evolution steps (i.e. local search iterations), the virtual frogs are shuffled and reorganized into new memeplexes in a method similar to that used in the shuffled complex evolution algorithm. In addition, to provide the chance for random generation of improved information, random virtual frogs are generated and substituted in the population if the local search cannot find better solutions. The local searches and the shuffling processes continue until the defined convergence criteria are satisfied, Nguyen [28]. The flowchart of the SFLA is shown in Fig. 1.

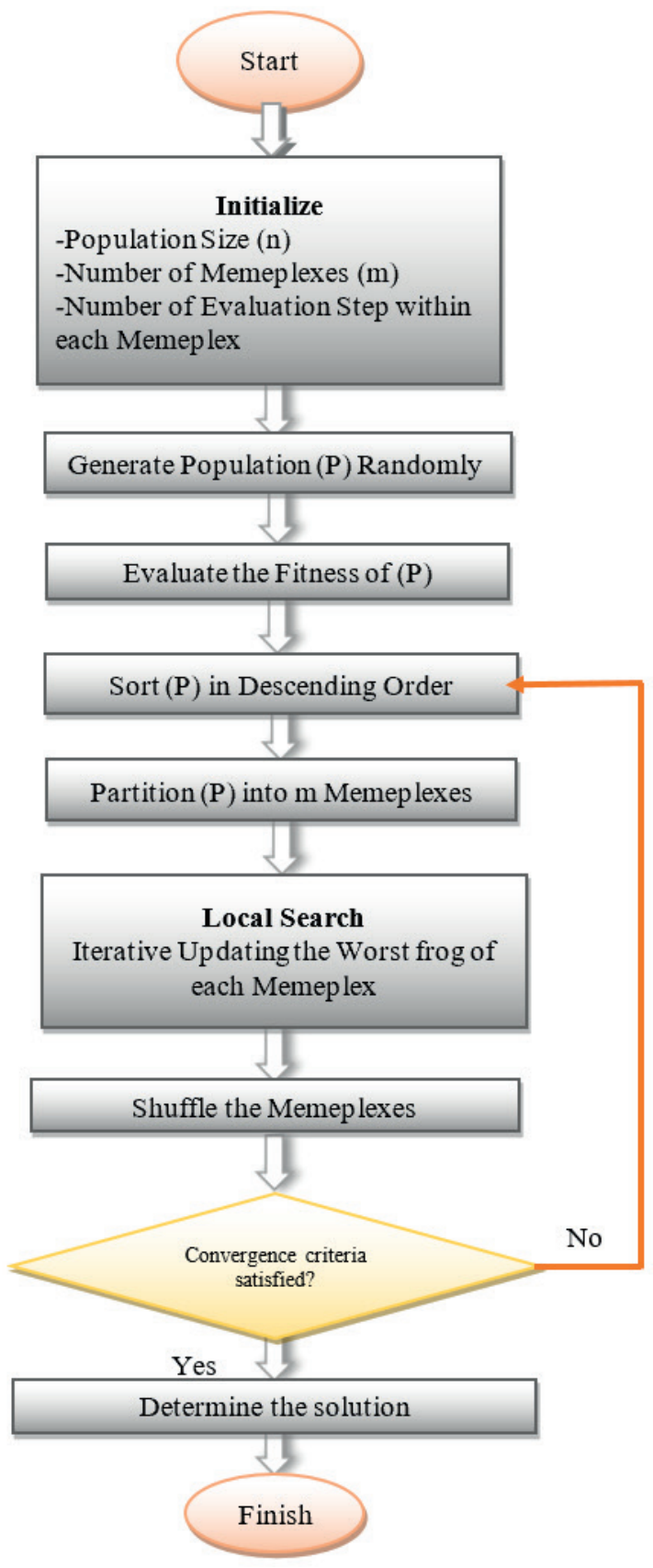

Fig. 1 Flowchart of the SFLA
The idea for updating frog leaping rule is expressed as:

$D=r . c\left(X_{b}-X_{w}\right)$

$X_{w}($ new $)=X_{w}+D$,

where, $X_{b}$ and $X_{w}$ are identified as the frogs with the best fitness and the worst fitness, respectively; $r$ is a random number between 0 and $1 ; c$, is a constant chosen in the range between 1 and 2, Huynh [29].

\subsection{Invasive weed optimization algorithm}

IWO algorithm is a bio-inspired numerical optimization algorithm which simply simulates natural behavior of weeds in colonizing and finding appropriate place for growth and reproduction, Mehrabian and Lucas [23]. A number of the distinct properties of IWO as compared with other evolutionary algorithms are the way of reproduction, spatial dispersal, and competitive exclusion. In the IWO algorithm, a population of initial solutions is randomly generated over the problem space. Then, members of the population produce seeds depending on their relative fitness. The number of seeds for each member is starting with the value of $S_{\min }$ for the worst member and increases linearly to $S_{\max }$ for the best member. For the third step, these seeds are randomly scattered over the search space by normally distributed random numbers with mean equal to zero and an adaptive standard deviation. For determining the standard deviation in each generation, the following equation is used (Eq. (13)):

$\sigma_{\text {iter }}=\frac{\left(\text { iter }_{\max }-\text { iter }\right)^{n}}{\left(\text { iter }_{\max }\right)^{n}}\left(\sigma_{\text {initial }}-\sigma_{\text {final }}\right)+\sigma_{\text {final }}$,

where $i t e r_{\text {max }}$ is the maximum number of iterations, $\sigma_{\text {iter }}$ is the standard deviation at the current iteration and $n$ is the nonlinear modulation index. The produced seeds, accompanied by their parents are considered as the potential solutions for the next generation. Finally, a competitive exclusion is conducted in the algorithm, i.e., after a number of iterations, the population reaches its maximum and an elimination mechanism has to be used. To this end, the seeds and their parents are ranked together and those with better fitness survive and become reproductive. The flowchart for this algorithm is provided in Fig. 2.

\subsection{The hybrid SFLA and IWo algorithms (sfla-iwo)}

From the two previous sub-sections, it can be observed that SFLA and IWO use two different approaches for optimization. The SFLA-IWO algorithm utilizes the shuffled 


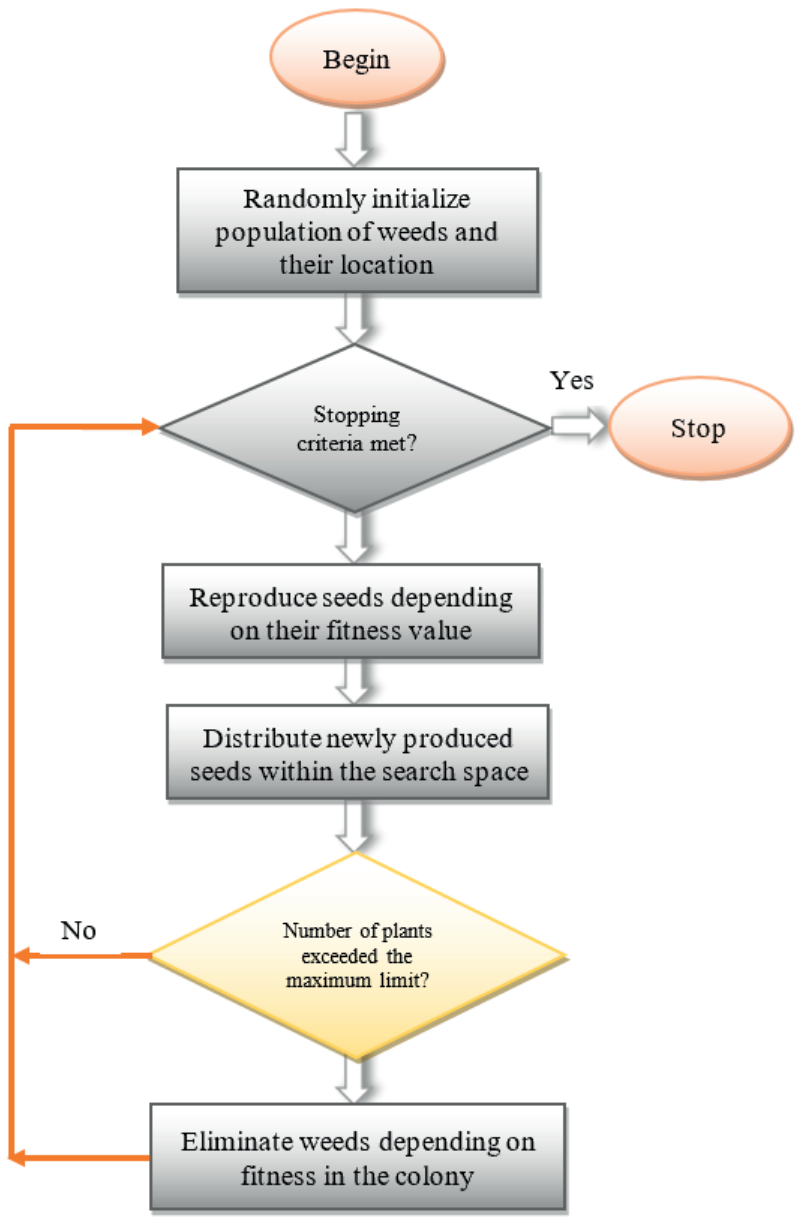

Fig. 2 Flowchart of the IWO

SFLA for finding optimal solution region rapidly and the IWO is used to exploit global solutions. Based on analyses of the strengths of SFLA and IWO, in the hybrid SFLAIWO algorithm [24] every memeplex evolves severally to locally search at totally different regions of the solution area within the SFLA. Then, the memeplexes are shuffled and re-divided into new memeplexes so as to globally seek through trading the data with one another. According to Eqs. $(11,12)$, when difference in position between $x_{w}$ and $x_{b}$ become small, the modification in the position of the frog $x_{w}$ (new) becomes small making the algorithm to be trapped in local optimum resulting in premature convergence. Moreover, information from the best frog is used only once in each update. For IWO algorithm, data from good seeds are utilized many times, remaining seeds in population are changed by random seeds. Thus, IWO tries to exploit around position of good seeds many times compared to SFLA. This enables the IWO to gain solution with better quality with seeking time being longer. While SFLA is capable of gaining solution quickly due to combining local and global seeking processes. After completing a generation of SFLA, the IWO is used with some changes. IWO updates their new agents around $m$ selected best seeds and $m$ worst seeds being replaced by random seeds. ( $m$ : number of memeplexes in SFLA).

In this section, these algorithms are combined and a hybrid SFLA-IWO algorithm is presented. This algorithm is executed in the following steps:

First, the initial population is created, and then, each memeplex is allocated a random position and the cost (light intensity) for that position is computed.

The next stage is to execute the SFL algorithm. During this step, based on the magnitude of the cost (light intensity) in each memeplex, if the pre-conditions of moving to another memeplex are not satisfied, then, it will be used to perform the process of updating in memeplex algorithm and population ought to be sorted.

Then, one has tendency to go to the subsequent step that performs the process of the IWO algorithm. In IWO algorithm phase, the generated weeds are randomly distributed over the search area by normally distributed random numbers with a mean equal to zero. Once all seeds have found their positions in the search space, they are ranked along with their parents (as a colony of weeds).

Next, weeds with lower fitness are eliminated to reach the maximum allowable population in a colony. In this way, weeds and seeds are ranked together and the ones with better fitness survive and are allowed to replicate.

The new memeplex that has been produced by the IWO is compared with the previous one. If the cost (light-intensity) for the newly-produced memeplex is better than the previous one, then it is swapped with the previous ones.

Then, the global best is also swapped with the new memeplex.

Finally, within the last step, if the termination criterion is satisfied, the ultimate best memeplex is considered as the output. Otherwise, the subsequent iterations should be started from memeplex algorithm once more [24].

\subsection{Sensitivity analysis for the hybrid of SFLA and IWO algorithm}

The 1-bay 8-story benchmark frame optimization problem is solved in order to find the parameter efficiency of the SFLA-IWO algorithm in this research. Fig. 3 shows the configuration of the 1-bay 8-story frame structure and applied loads. The assumed material density is $76.8 \mathrm{kN} / \mathrm{m}^{3}$ $\left(7831.43 \mathrm{~kg} / \mathrm{m}^{3}\right)$ and the modulus of elasticity is $200 \mathrm{GPa}$. This frame optimization problem has 8 design variables. Effect of each input parameter on the results is evaluated 


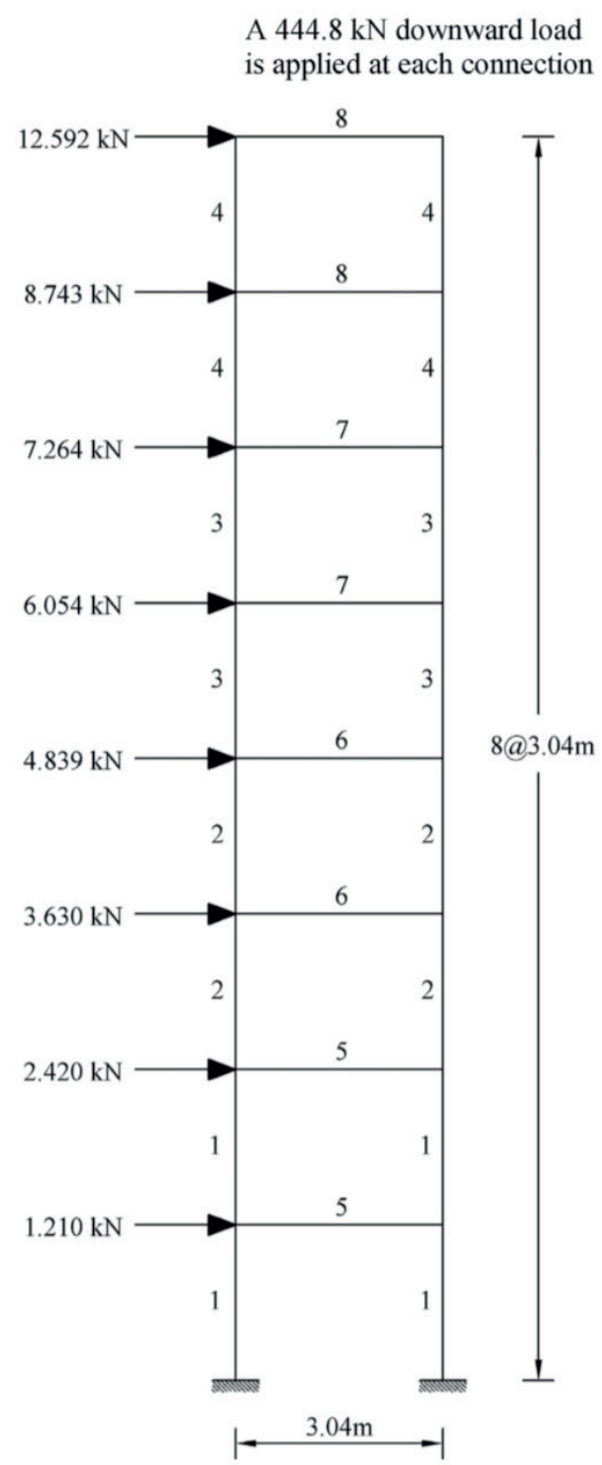

to find the optimum values through sensitivity analysis. SFLA-IWO includes six important parameters. These six parameters are exponent, memeplex size, number of memeplexes, number of off-springs, maximum number of iterations and step size. Analysis of the 1-bay 8-story with SFLA-IWO algorithm is started by the base parameters, then the program is run with 6 different parameters and 10 times for each parameter (900 000 runs). In each phase, the best result of 10 runs are evaluated, reported and stored for each parameter. Finally, the best values of the parameters with the lowest standard deviation and iteration are recorded. Likewise, the sensitivity of results to input parameters is discussed herein. At the end, the best values of input parameters with their standard deviation are presented in Fig. 4. The effect of parameters on the results of the SFLA-IWO algorithm is analyzed. Table 1 presents the best values of each parameter with the minimum value of standard deviation.

Table 1 Parameters of SFLA-IWO

\begin{tabular}{|c|c|c|c|c|c|c|c|}
\hline 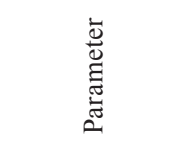 & & 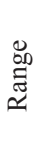 & & $\begin{array}{l}\frac{\pi}{0} \\
\stackrel{0}{0} \\
\end{array}$ & 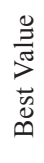 & 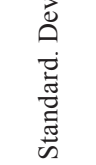 & $\begin{array}{l}\vec{w} \\
0 \\
0 \\
\tilde{n} \\
0 \\
0\end{array}$ \\
\hline Exponent & {$[1$} & $\sim$ & 5] & 1 & 2 & 0.2657 & 31.1912 \\
\hline nMemeplex & {$[1$} & & 10] & 2 & 5 & 0.1154 & 31.3332 \\
\hline nPopMemeplex & {$[10$} & $\sim$ & 50] & 10 & 10 & 0.1843 & 31.0984 \\
\hline Sigma & {$[1$} & $\sim$ & 5] & 1 & 4 & 0.2013 & 31.2621 \\
\hline Alpha & {$[1$} & $\sim$ & 5] & 1 & 5 & 0.2856 & 31.0884 \\
\hline Beta & {$[1$} & $\sim$ & 5] & 1 & 5 & 0.2998 & 31.2458 \\
\hline
\end{tabular}

Fig. 3 The 1-bay 8-story frame and the loading

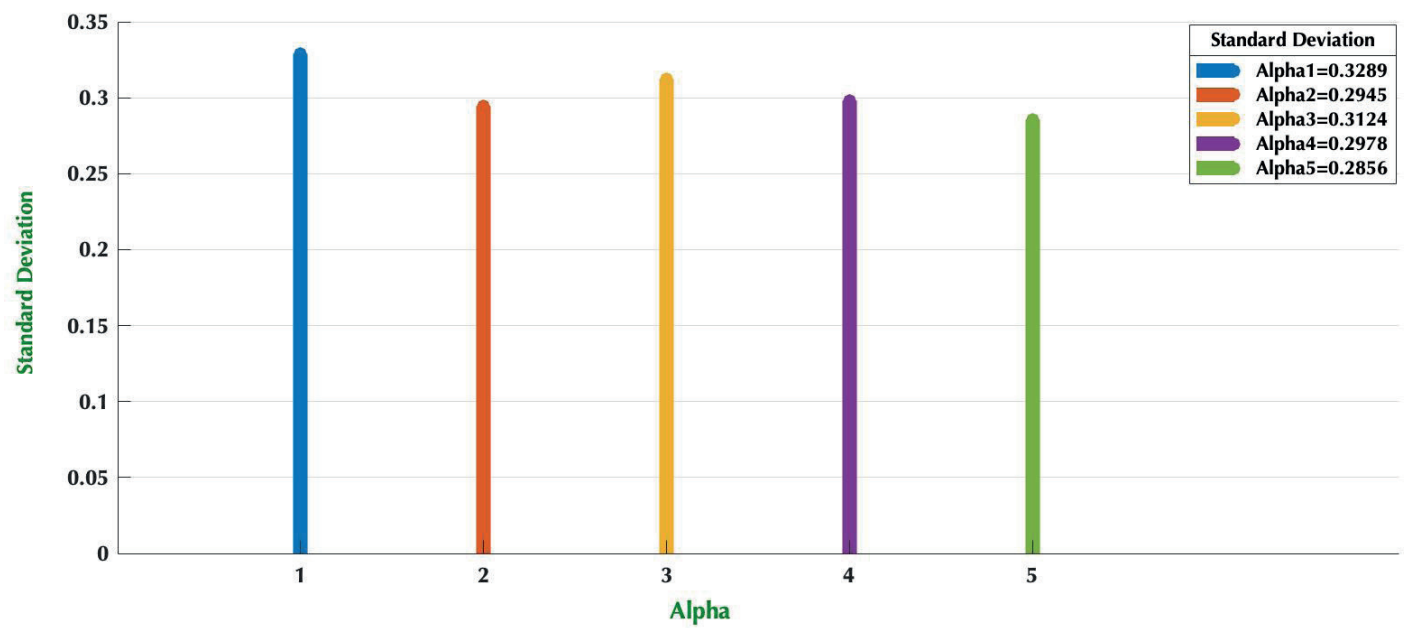

(a) 


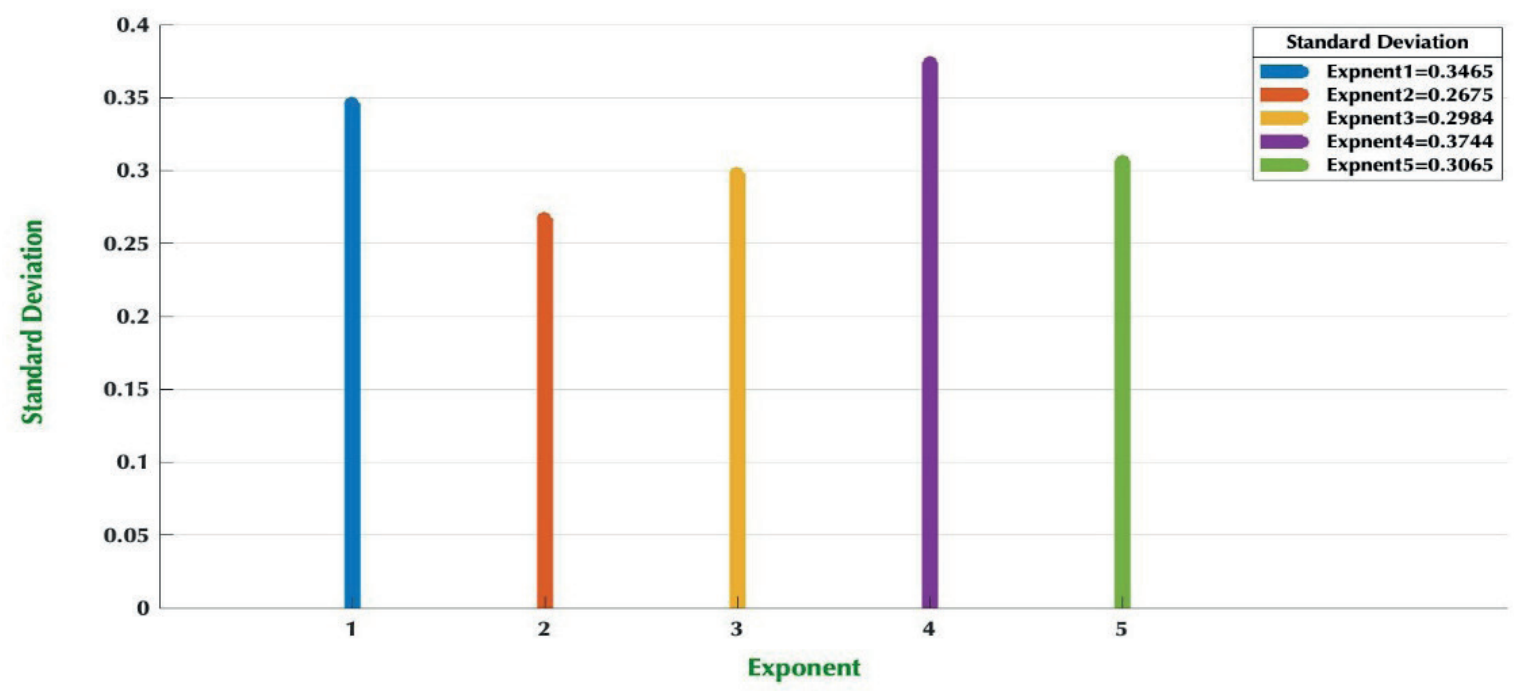

(b)

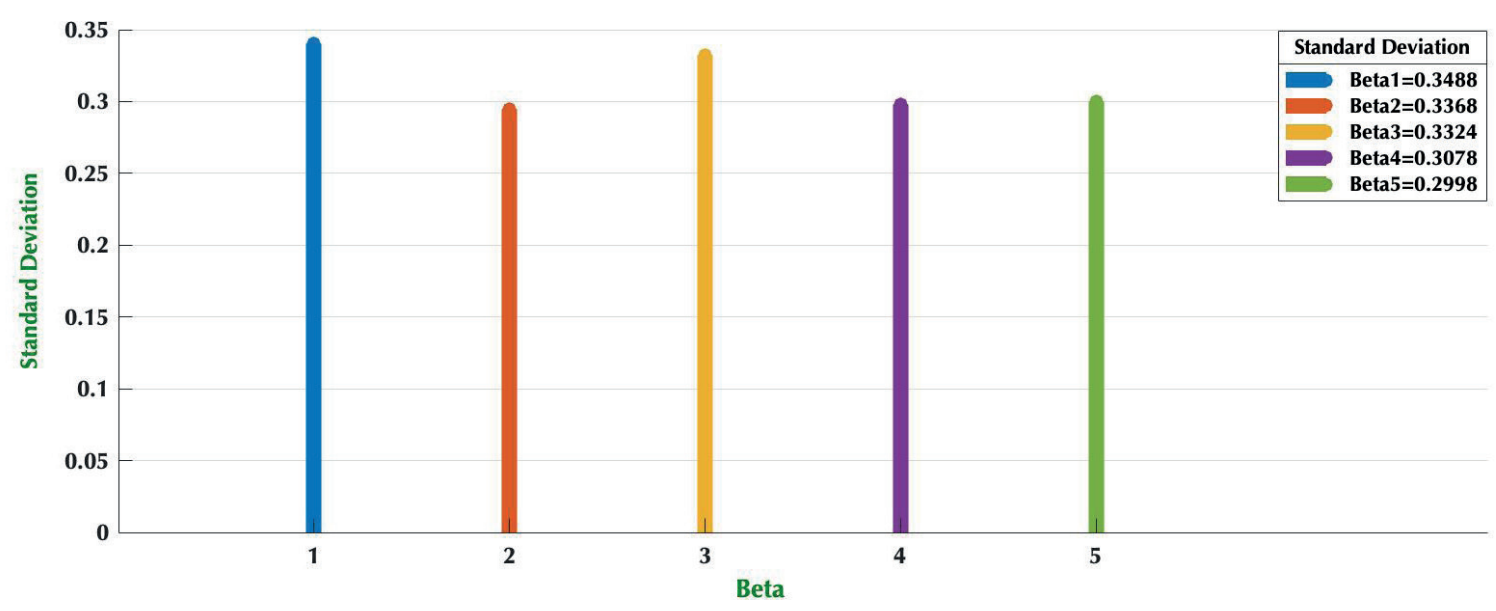

(c)

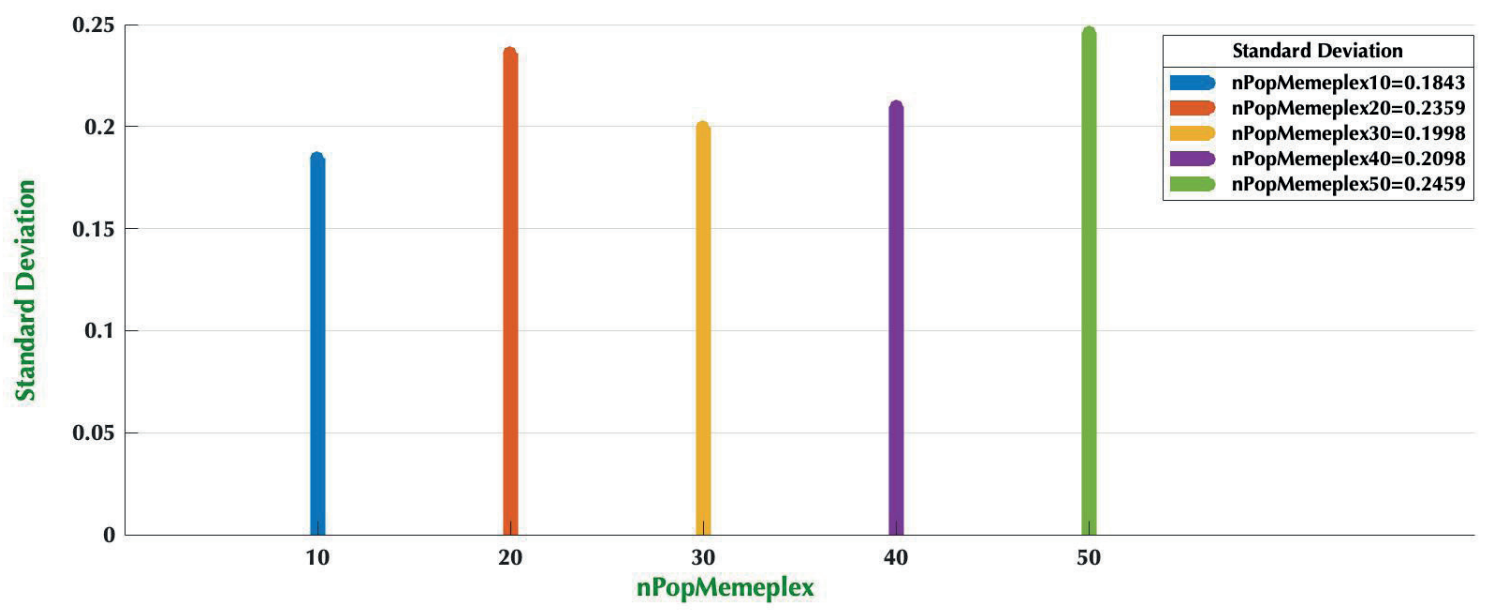

(d) 


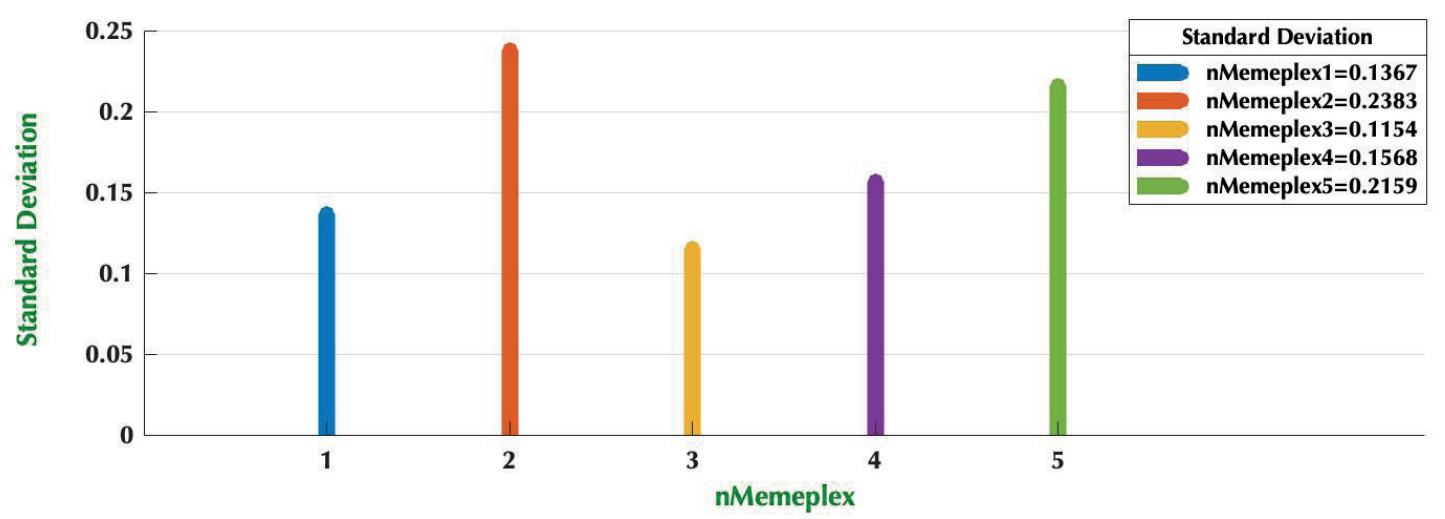

(e)

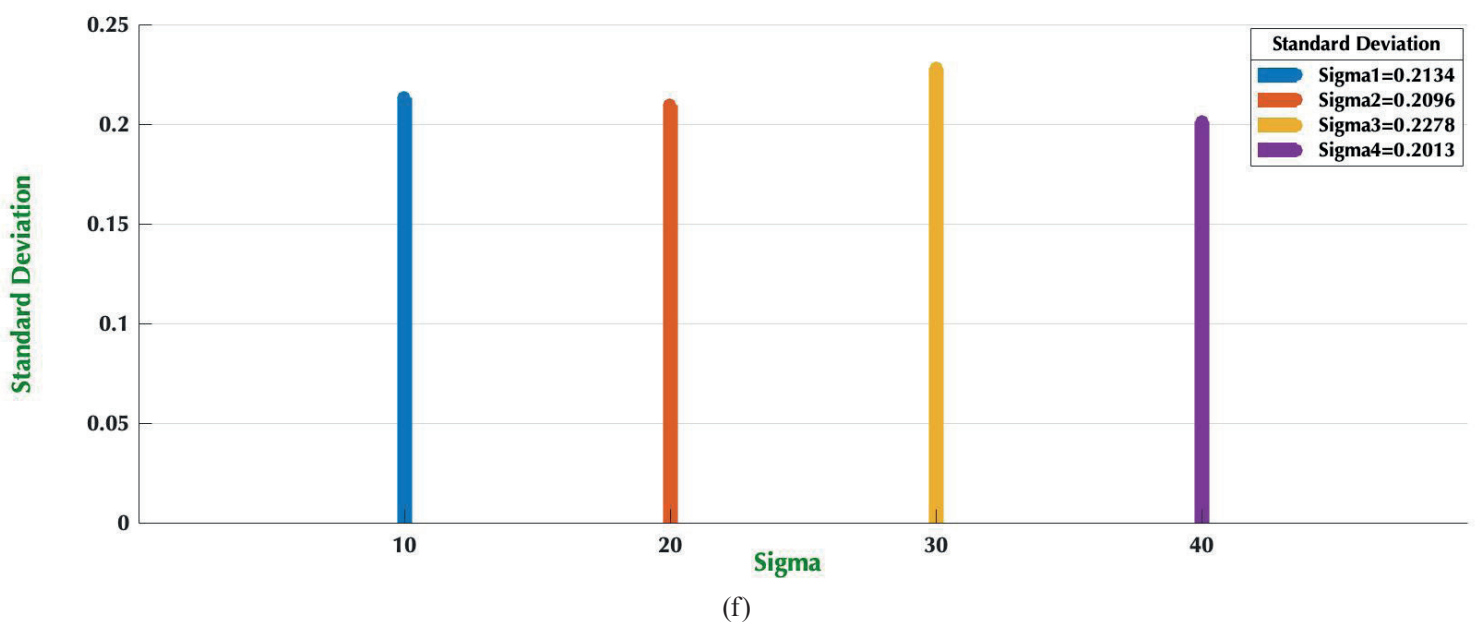

Fig. 4 The sensitivity analysis of parameters of SFLA-IWO

\section{Numerical examples}

This section presents the numerical examples of three frames benchmark optimization to evaluate the potentiality of the utilized algorithm in determining the optimal design of frame structures. These problems include: A 1-bay 8-story frame, A 3-bay 15-story frame, A 3-bay 24-story frame for investigating the performance of the SFLA-IWO and the final results are compared to the solutions of some other hybrid algorithms to show the efficiency of the present approach. It should be noted that the purpose of optimal solution is to find the best answer among answers for each algorithm.

In this paper, a population of 50 individuals is used for the SFLA-IWO algorithm and two hundred iterations are performed as the maximum number of iterations. For more precise study, each problem is solved 40 times independently. The utilized algorithm is coded in Matlab and structures are analyzed using the direct stiffness method. The steel members used for the design consist of $\mathrm{W}$-shaped sections from the AISC database. The present work is performed on the computer with following features: CPU 3.3 GHZ (an Intel Core i7 computer platform), Ram 16 GB and Matlab 2018 running on computer with Macintosh (macOS Mojave) and for CPU with limited resource, higher values of control parameters may cause CPU to freeze and RAM to overflow.

\subsection{Example one: The 1-Bay 8- Story Frame}

The 1-Bay 8-story steel frame with applied loads depicted in Fig. 1 is studied as the first example. The material properties of steel are: modulus of elasticity $(E)=200 \mathrm{GPa}$ and unit weight of the steel $(q)=76.8 \mathrm{kN} / \mathrm{m}^{3}$. The lateral drift at the top of the structure is the only performance constraint (limited to $5.08 \mathrm{~cm}$ ). Members of the mentioned frame are categorized into 8 groups selected from a list of AISC database. The optimum design of the frame obtained by using SFLA-IWO has the minimum weight of $31.08 \mathrm{kN}$. Table 2 compares the results obtained by the SFLA-IWO with the standard IWO and SFLA. It can be observed that the design obtained by the SFLAIWO method is much better than the results obtained the SFLA or IWO. Several researchers have developed 
design procedures for this frame. The optimum designs for the PSOPC (Kaveh and Talatahari [30]), HGAPSO (Kaveh and Malakoutirad [19]) and PSACO (Kaveh and Talatahari [30]) had the weight of $34.21 \mathrm{kN}, 31.24 \mathrm{kN}$ and $32.29 \mathrm{kN}$, respectively. Table 3 lists the optimal values of the eight design variables obtained by this research, and compares with other results. Fig. 5 provides the convergence histories for this example obtained by the SFLAIWO in comparison with others. This figure shows that in initial iterations, the SFLA-IWO can find some good results very soon, and it does not need high number of iterations. It is observed that the standard deviation of the SFLA-IWO is less than those of the standard basic algorithms, showing lower scattering of the SFLA-IWO solution and it can be seen that the SFLA-IWO can find the better design and its CPU time is quite comparable with those of the other optimization algorithms.

\subsection{Example two: The 3-Bay 15-Story Frame}

The configuration and applied loads of a 3-bay 15-story steel frame structure is illustrated in Fig. 6. The material properties of steel are: modulus of elasticity $(E)=200 \mathrm{GPa}$, yield stress $\left(F_{y}\right)=248.2 \mathrm{MPa}$, and unit weight of the steel $(q)=7.85 \mathrm{Ton} / \mathrm{m}^{3}$.

The effective length factors of the members are calculated as for a sway-permitted frame and the out-of-plane effective length factor is specified as. Each column is considered as non-braced along its length, and the unbraced length for each beam member is specified as one-fifth of the span length.
Table 2 Comparison of the optimization result obtained in 1-bay 8-story problem with SFLA and IWO algorithms

\begin{tabular}{lccc}
\hline Element Group & IWO & SFLA & $\begin{array}{c}\text { Present Work } \\
\text { SFLA-IWO }\end{array}$ \\
\hline 1 & $\mathrm{~W} 21 \times 50$ & $\mathrm{~W} 24 \times 62$ & $\mathrm{~W} 18 \times 40$ \\
2 & $\mathrm{~W} 16 \times 26$ & $\mathrm{~W} 16 \times 26$ & $\mathrm{~W} 18 \times 35$ \\
3 & $\mathrm{~W} 14 \times 26$ & $\mathrm{~W} 14 \times 34$ & $\mathrm{~W} 14 \times 22$ \\
4 & $\mathrm{~W} 12 \times 16$ & $\mathrm{~W} 12 \times 14$ & $\mathrm{~W} 12 \times 14$ \\
5 & $\mathrm{~W} 21 \times 48$ & $\mathrm{~W} 12 \times 14$ & $\mathrm{~W} 18 \times 35$ \\
6 & $\mathrm{~W} 16 \times 31$ & $\mathrm{~W} 21 \times 50$ & $\mathrm{~W} 18 \times 35$ \\
7 & $\mathrm{~W} 16 \times 31$ & $\mathrm{~W} 18 \times 35$ & $\mathrm{~W} 18 \times 35$ \\
8 & $\mathrm{~W} 14 \times 22$ & $\mathrm{~W} 14 \times 26$ & $\mathrm{~W} 14 \times 22$ \\
Weight $(\mathrm{kN})$ & 32.75 & 35.38 & 31.08 \\
Number of Analyses & 10000 & 10000 & 10000 \\
\hline
\end{tabular}

Table 3 Comparison of optimized 1-bay 8-story frame obtained through SFLA-IWO with other hybrid algorithms

\begin{tabular}{lcccc}
\hline & & 0 & & \\
\hline 1 & W18 $\times 35$ & $\mathrm{~W} 18 \times 35$ & $\mathrm{~W} 18 \times 35$ & $\mathrm{~W} 18 \times 40$ \\
2 & $\mathrm{~W} 16 \times 31$ & $\mathrm{~W} 18 \times 35$ & $\mathrm{~W} 14 \times 26$ & $\mathrm{~W} 18 \times 35$ \\
3 & $\mathrm{~W} 14 \times 22$ & $\mathrm{~W} 14 \times 22$ & $\mathrm{~W} 16 \times 26$ & $\mathrm{~W} 14 \times 22$ \\
4 & $\mathrm{~W} 12 \times 16$ & $\mathrm{~W} 12 \times 16$ & $\mathrm{~W} 14 \times 26$ & $\mathrm{~W} 12 \times 14$ \\
5 & $\mathrm{~W} 21 \times 48$ & $\mathrm{~W} 16 \times 31$ & $\mathrm{~W} 24 \times 62$ & $\mathrm{~W} 18 \times 35$ \\
6 & $\mathrm{~W} 18 \times 40$ & $\mathrm{~W} 21 \times 44$ & $\mathrm{~W} 18 \times 35$ & $\mathrm{~W} 18 \times 35$ \\
7 & $\mathrm{~W} 16 \times 31$ & $\mathrm{~W} 18 \times 35$ & $\mathrm{~W} 16 \times 31$ & $\mathrm{~W} 18 \times 35$ \\
8 & $\mathrm{~W} 16 \times 36$ & $\mathrm{~W} 16 \times 26$ & $\mathrm{~W} 12 \times 30$ & $\mathrm{~W} 14 \times 22$ \\
$\mathrm{Weight}(\mathrm{kN})$ & 32.29 & 31.243 & 34.21 & 31.08 \\
\hline
\end{tabular}

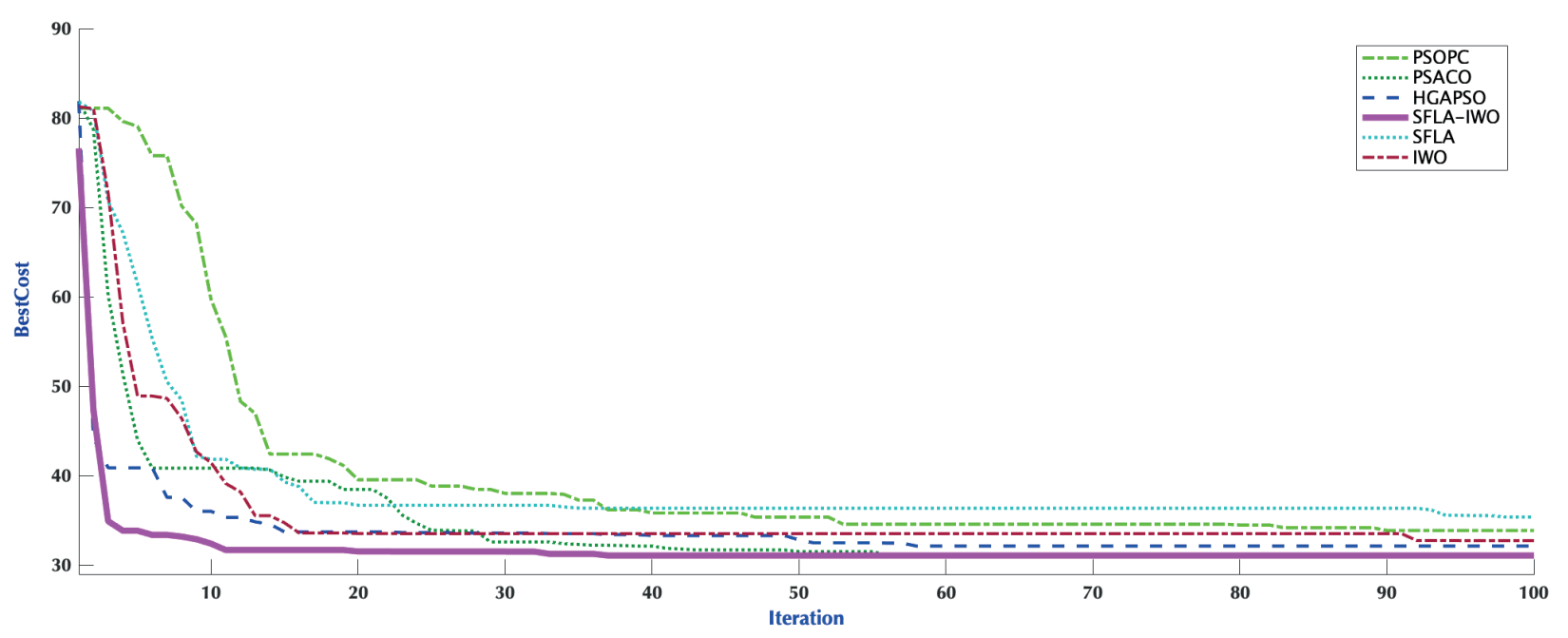

Fig. 5 Convergence of the 1- bay 8-story 
$\mathrm{w}_{1}=50 \mathrm{kN} / \mathrm{m}$

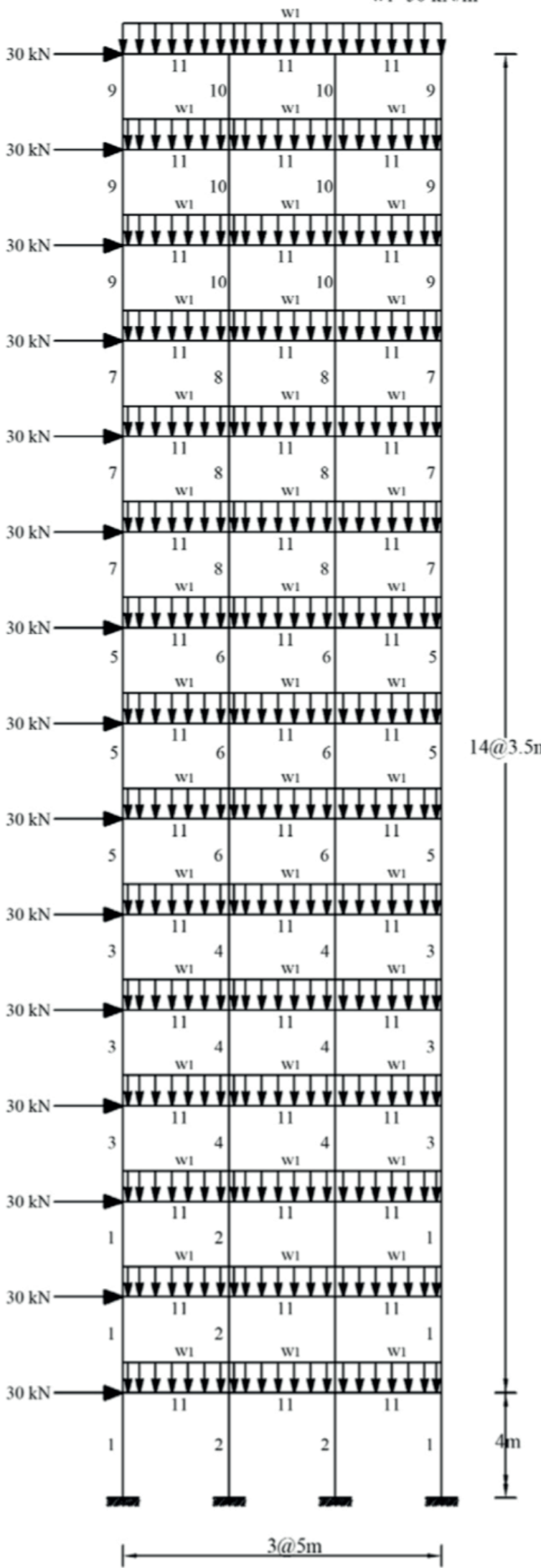

Fig. 6 The 3-bay 15-story frame and the loading
This example is also is solved by the standard SFLA and IWO algorithms in addition to the SFLA-IWO and the results of optimization are reported in Table 4. Again, the table shows that the hybrid algorithm has better performance. The optimum design of the frame has the minimum weight of $379.21 \mathrm{kN}$. The optimum designs for PSOPC (Kaveh and Talatahari [30]), HPSACO (Kaveh and Talatahari [21]), HBB-BC (Kaveh and Talatahari [14]), GSU-PSO (Khajeh et al. [32]) and CBO-MDM (Kaveh et al. [33]) had the weight of $452.34 \mathrm{kN}, 426.36 \mathrm{kN}$, $434.54 \mathrm{kN}, 396.74 \mathrm{kN}$ and $387.45 \mathrm{kN}$, respectively. Results of the present study and those of reported in (Kaveh and Talatahari [14], Khajeh et al. [32], Kaveh et al. [33]) are compared in Table 5. In Fig. 7, the convergence curves of some hybrid algorithms are presented. Fig. 8 shows the ratio of the inter-story drift to the allowable inter-story drift in the optimum frame design. It is noted that the optimum design of the frame was obtained after 10000 analyses (100 iterations) by using SFLA-IWO and the best weight belongs to SFLA-IWO. This is $19.28 \%$ lighter than the design obtained by the PSOPC, $12.43 \%$ lighter than the result of the HPSACO, $14.59 \%$ lighter than that of the HBB-BC, $4.62 \%$ lighter than that of the GSU-PSO and $2.17 \%$ lighter than the design obtained by CBO-MDM. Element stress ratios evaluated at the best design optimized by SFLA-IWO are illustrated in Fig. 9.

\begin{tabular}{|c|c|c|c|}
\hline Element Group & IWO & SFLA & $\begin{array}{c}\text { Present } \\
\text { Work } \\
\text { SFLA-IWO }\end{array}$ \\
\hline 1 & $\mathrm{~W} 18 \times 106$ & $\mathrm{~W} 18 \times 106$ & $\mathrm{~W} 14 \times 90$ \\
\hline 2 & $\mathrm{~W} 33 \times 152$ & $\mathrm{~W} 24 \times 146$ & $\mathrm{~W} 26 \times 146$ \\
\hline 3 & W26 × 84 & $\mathrm{~W} 12 \times 79$ & $\mathrm{~W} 18 \times 76$ \\
\hline 4 & $\mathrm{~W} 24 \times 104$ & W26 × 114 & $\mathrm{~W} 24 \times 104$ \\
\hline 5 & $\mathrm{~W} 12 \times 87$ & $\mathrm{~W} 14 \times 74$ & $\mathrm{~W} 12 \times 72$ \\
\hline 6 & $\mathrm{~W} 14 \times 90$ & $\mathrm{~W} 18 \times 86$ & $\mathrm{~W} 18 \times 86$ \\
\hline 7 & $\mathrm{~W} 18 \times 71$ & $\mathrm{~W} 18 \times 65$ & $\mathrm{~W} 12 \times 58$ \\
\hline 8 & $\mathrm{~W} 18 \times 60$ & $\mathrm{~W} 18 \times 60$ & $\mathrm{~W} 14 \times 61$ \\
\hline 9 & $\mathrm{~W} 10 \times 33$ & $\mathrm{~W} 6 \times 20$ & $\mathrm{~W} 6 \times 25$ \\
\hline 10 & $\mathrm{~W} 10 \times 33$ & $\mathrm{~W} 14 \times 38$ & $\mathrm{~W} 16 \times 36$ \\
\hline 11 & $\mathrm{~W} 21 \times 44$ & $\mathrm{~W} 21 \times 44$ & $\mathrm{~W} 21 \times 44$ \\
\hline Weight $(\mathrm{kN}) \times$ & 399.78 & 389.77 & 379.21 \\
\hline Number of Analyses & 10000 & 10000 & 10000 \\
\hline
\end{tabular}




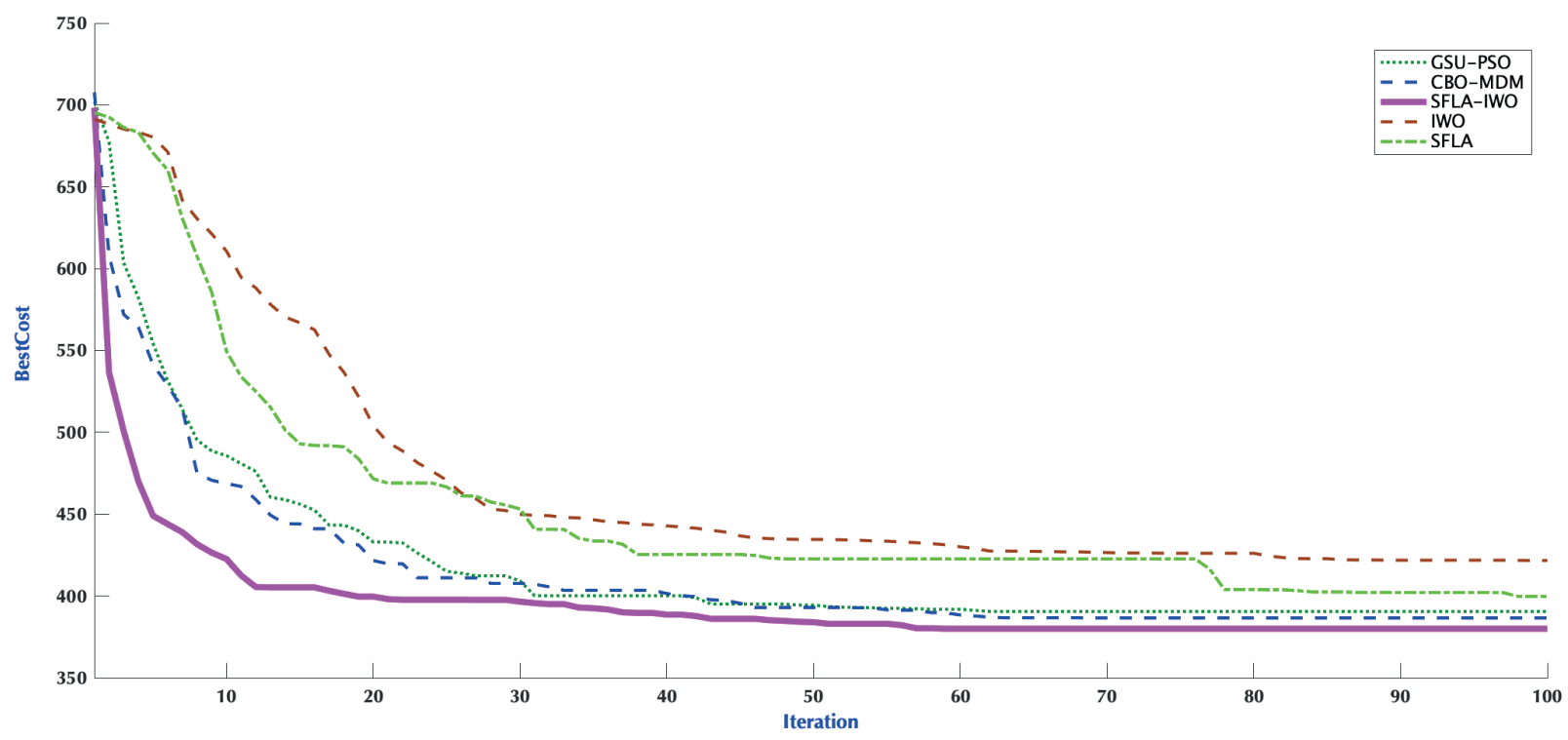

Fig. 7 Convergence of the 3-bay 15-story

Table 5 Comparison of optimized 3-bay 15-story frame obtained through SFLA-IWO with other hybrid algorithms

\begin{tabular}{|c|c|c|c|c|c|c|}
\hline Element Group & $\begin{array}{c}\text { HPSACO } \\
{[21]}\end{array}$ & $\begin{array}{c}\text { HBB-BC } \\
{[14]}\end{array}$ & $\begin{array}{c}\text { PSOPC } \\
{[30]}\end{array}$ & $\begin{array}{c}\text { GSU-PSO } \\
\text { [32] }\end{array}$ & $\begin{array}{c}\text { CBO-MDM } \\
\text { [32] }\end{array}$ & $\begin{array}{c}\text { Present Work } \\
\text { SFLA-IWO }\end{array}$ \\
\hline 1 & $\mathrm{~W} 21 \times 111$ & W24 × 117 & W26 × 129 & W21 $\times 44$ & $\mathrm{~W} 14 \times 99$ & $\mathrm{~W} 14 \times 90$ \\
\hline 2 & $\mathrm{~W} 18 \times 158$ & $\mathrm{~W} 21 \times 132$ & $\mathrm{~W} 24 \times 131$ & $\mathrm{~W} 12 \times 106$ & $\mathrm{~W} 27 \times 161$ & W26 × 146 \\
\hline 3 & $\mathrm{~W} 10 \times 88$ & $\mathrm{~W} 12 \times 95$ & $\mathrm{~W} 24 \times 103$ & $\mathrm{~W} 27 \times 161$ & $\mathrm{~W} 14 \times 82$ & $\mathrm{~W} 18 \times 76$ \\
\hline 4 & $\mathrm{~W} 30 \times 116$ & $\mathrm{~W} 18 \times 119$ & $\mathrm{~W} 33 \times 141$ & W27 × 84 & $\mathrm{~W} 24 \times 104$ & W24 × 104 \\
\hline 5 & $\mathrm{~W} 21 \times 83$ & $\mathrm{~W} 21 \times 93$ & W24 × 104 & $\mathrm{~W} 27 \times 114$ & $\mathrm{~W} 16 \times 67$ & $\mathrm{~W} 12 \times 72$ \\
\hline 6 & $\mathrm{~W} 24 \times 103$ & $\mathrm{~W} 18 \times 97$ & $\mathrm{~W} 10 \times 88$ & $\mathrm{~W} 16 \times 67$ & $\mathrm{~W} 18 \times 86$ & $\mathrm{~W} 18 \times 86$ \\
\hline 7 & $\mathrm{~W} 21 \times 55$ & $\mathrm{~W} 18 \times 76$ & $\mathrm{~W} 14 \times 74$ & $\mathrm{~W} 18 \times 86$ & $\mathrm{~W} 21 \times 48$ & $\mathrm{~W} 12 \times 58$ \\
\hline 8 & W26 × 114 & $\mathrm{~W} 18 \times 65$ & W26 × 94 & $\mathrm{~W} 24 \times 55$ & $\mathrm{~W} 14 \times 61$ & $\mathrm{~W} 14 \times 61$ \\
\hline 9 & $\mathrm{~W} 10 \times 33$ & $\mathrm{~W} 18 \times 60$ & $\mathrm{~W} 21 \times 57$ & $\mathrm{~W} 16 \times 67$ & $\mathrm{~W} 8 \times 28$ & $\mathrm{~W} 6 \times 25$ \\
\hline 10 & $\mathrm{~W} 18 \times 46$ & $\mathrm{~W} 10 \times 39$ & $\mathrm{~W} 18 \times 71$ & $\mathrm{~W} 8 \times 24$ & $\mathrm{~W} 10 \times 39$ & $\mathrm{~W} 16 \times 36$ \\
\hline 11 & $\mathrm{~W} 21 \times 44$ & $\mathrm{~W} 21 \times 48$ & $\mathrm{~W} 21 \times 44$ & $\mathrm{~W} 16 \times 45$ & $\mathrm{~W} 21 \times 44$ & $\mathrm{~W} 21 \times 44$ \\
\hline Weight (kN) & 426.36 & 434.54 & 452.34 & 396.74 & 387.45 & 379.21 \\
\hline
\end{tabular}

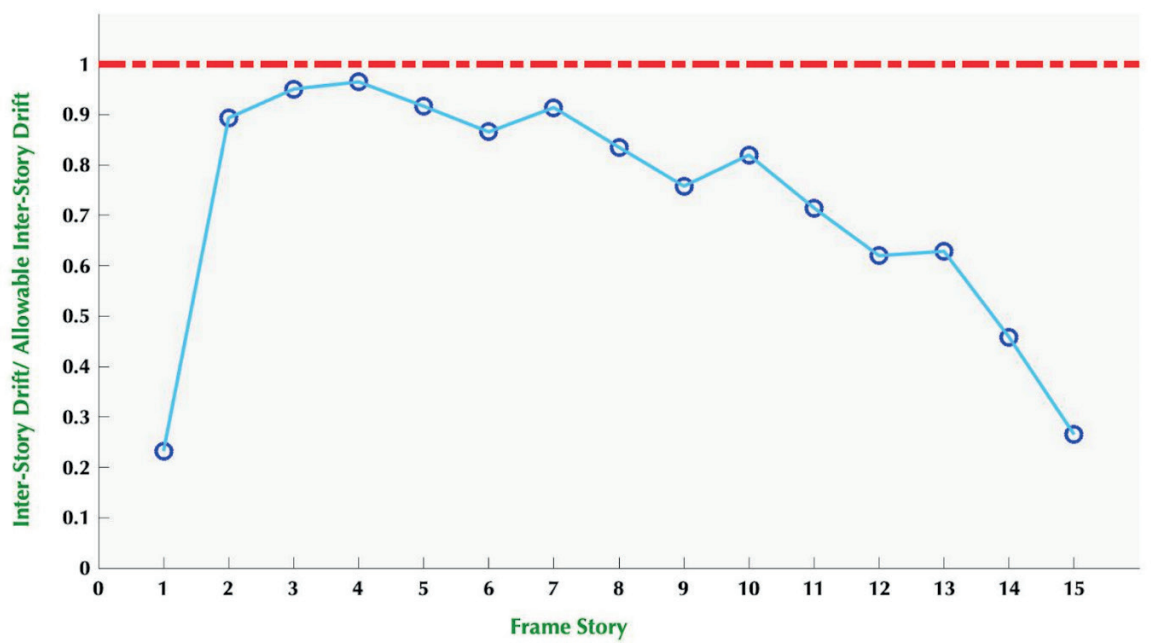

Fig. 8 The ratio of the inter-story drift to the allowable inter-story drift in the optimum frame design for the 3-bay 15-story 


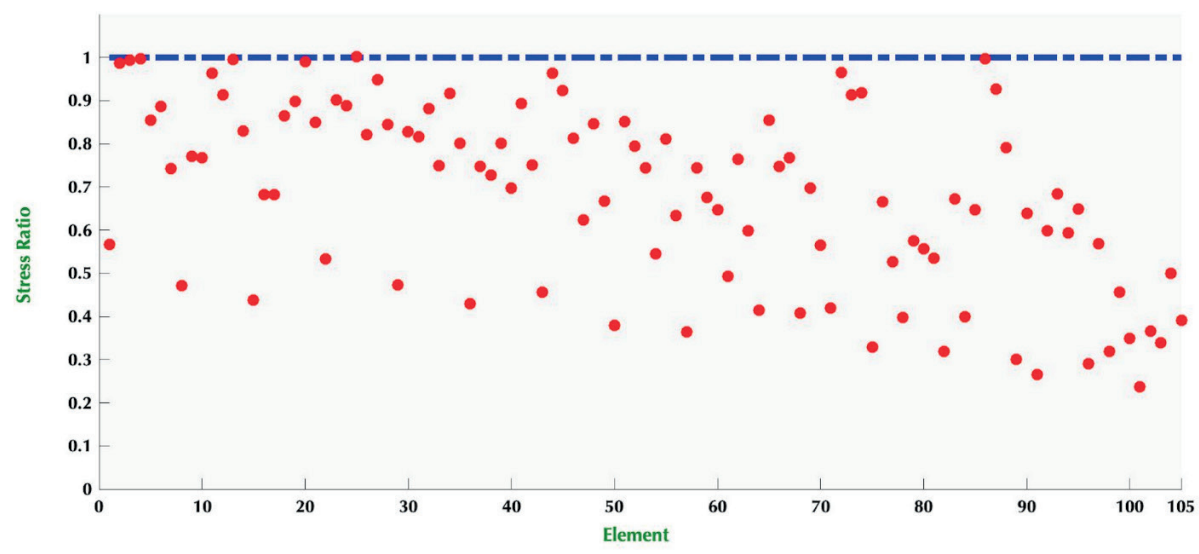

Fig. 9 The element stress ratio in the optimum frame design for the 3-bay 15-story

\subsection{Example three: The 3-Bay 24- Story Frame}

The schematic of the 3-bay 24-story frame consisting of 100 joints and 168 members and the loads applied to the structure are illustrated in Fig. 10. All members are created of steel: the material density and modulus of elasticity are $0.283 \mathrm{lb} / \mathrm{in}^{3}\left(7933.41 \mathrm{~kg} / \mathrm{m}^{3}\right)$ and $30 \mathrm{Msi}(205 \mathrm{GPa})$ and yield stress $(F y)=230.3 \mathrm{MPa}$, respectively. The effective length factors of the members are calculated as $K_{x} \geq 0$ for a sway-permitted frame and the out-of-plane effective length factor is specified as $K_{y}=1$. Each column is considered as non-braced along its length, and the unbraced length for each beam member is specified as one-fifth of the span length. Fabrication conditions are imposed on the construction of the 168-element frame requiring that the same beam section be used in the first and third bay on all floors except the roof beams, resulting in four beam groups. Beginning at the foundation, the exterior columns are combined into one group and the interior columns are combined together in another group over three consecutive stories. The grouping results in 16 column sections and 4 beam sections for a total of 20 design variables. In this example, each of the four beam element groups is chosen from all $267 \mathrm{~W}$-shapes, while the 16 column element groups are limited to W14 sections (37 W-shapes). Several researchers have implemented design procedures for this frame; Kaveh et al. [33] implemented heuristic Big Bang-Big Crunch Particle Swarm algorithm, Kaveh and Talatahari [14] applied a hybrid Big Bang-Big Crunch optimization and Khajeh et al. [32] hybridized the particle swarm optimization, grid search method and univariate method and used to solve this problem.

The 3-bay 24-story frame are optimized by SFLA and IWO algorithms in order to compare with utilized hybrid method, and the results are reported in Table 6. For these algorithms, convergence curves are shown in Fig. 11. It is

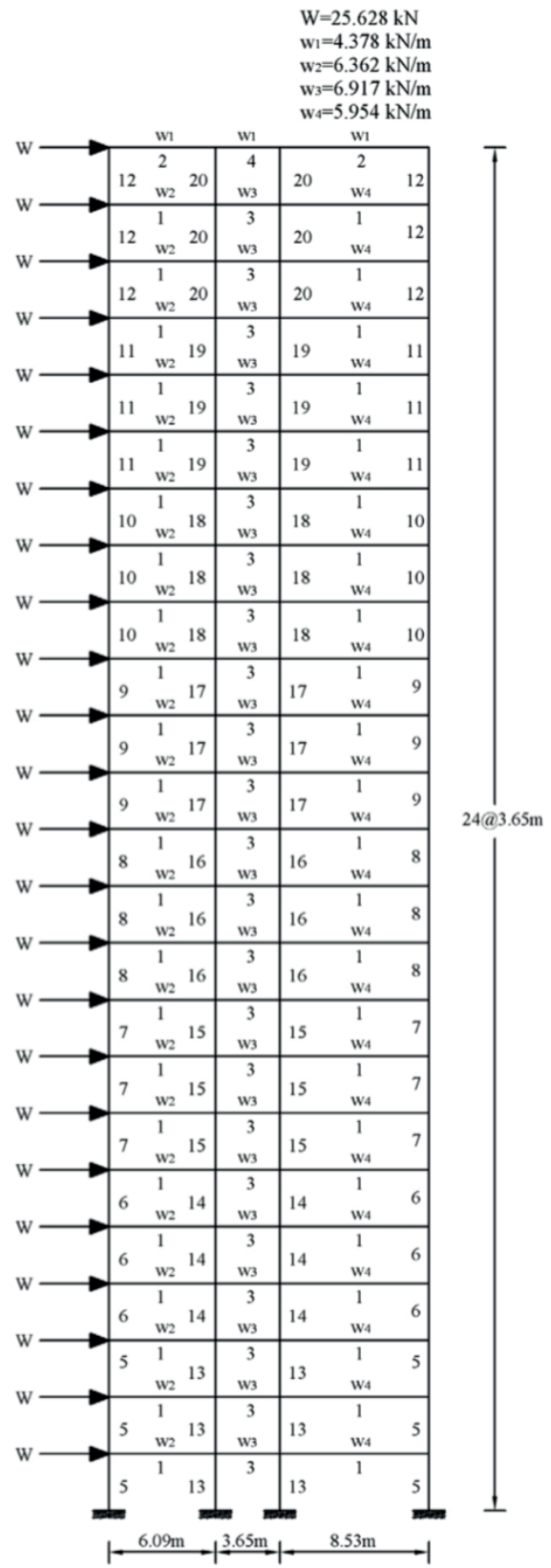

Fig. 10 The 3-bay 24-story frame and the loading 
Table 6 Comparison of the optimization result obtained in 3-bay 24-story problem with SFLA and IWO algorithms

\begin{tabular}{|c|c|c|c|}
\hline Element Group & IWO & SFLA & $\begin{array}{l}\text { Present Work } \\
\text { SFLA-IWO }\end{array}$ \\
\hline 1 & $\mathrm{~W} 30 \times 90$ & $\mathrm{~W} 30 \times 90$ & $\mathrm{~W} 30 \times 90$ \\
\hline 2 & $\mathrm{~W} 21 \times 48$ & $\mathrm{~W} 21 \times 48$ & $\mathrm{~W} 21 \times 48$ \\
\hline 3 & $\mathrm{~W} 21 \times 44$ & W $24 \times 62$ & W $21 \times 48$ \\
\hline 4 & $\mathrm{~W} 18 \times 46$ & $\mathrm{~W} 12 \times 19$ & $\mathrm{~W} 12 \times 19$ \\
\hline 5 & $\mathrm{~W} 14 \times 311$ & $\mathrm{~W} 14 \times 132$ & $\mathrm{~W} 14 \times 176$ \\
\hline 6 & $\mathrm{~W} 14 \times 132$ & W14 × 109 & W14 × 109 \\
\hline 7 & $\mathrm{~W} 14 \times 90$ & $\mathrm{~W} 14 \times 99$ & W14 × 109 \\
\hline 8 & $\mathrm{~W} 14 \times 159$ & $\mathrm{~W} 14 \times 68$ & $\mathrm{~W} 14 \times 90$ \\
\hline 9 & $\mathrm{~W} 14 \times 48$ & $\mathrm{~W} 14 \times 90$ & $\mathrm{~W} 14 \times 90$ \\
\hline 10 & $\mathrm{~W} 14 \times 43$ & $\mathrm{~W} 14 \times 159$ & $\mathrm{~W} 14 \times 48$ \\
\hline 11 & $\mathrm{~W} 14 \times 30$ & $\mathrm{~W} 14 \times 30$ & $\mathrm{~W} 14 \times 30$ \\
\hline 12 & $\mathrm{~W} 14 \times 26$ & $\mathrm{~W} 14 \times 30$ & $\mathrm{~W} 14 \times 34$ \\
\hline 13 & W14 × 68 & W14 × 99 & $\mathrm{~W} 14 \times 90$ \\
\hline 14 & $\mathrm{~W} 14 \times 120$ & $\mathrm{~W} 14 \times 109$ & $\mathrm{~W} 14 \times 120$ \\
\hline 15 & $\mathrm{~W} 14 \times 193$ & W14 × 99 & W14 × 99 \\
\hline 16 & $\mathrm{~W} 14 \times 53$ & $\mathrm{~W} 14 \times 120$ & $\mathrm{~W} 14 \times 90$ \\
\hline 17 & $\mathrm{~W} 14 \times 82$ & $\mathrm{~W} 14 \times 90$ & $\mathrm{~W} 14 \times 61$ \\
\hline 18 & W14 × 61 & $\mathrm{~W} 14 \times 38$ & $\mathrm{~W} 14 \times 53$ \\
\hline 19 & $\mathrm{~W} 14 \times 38$ & $\mathrm{~W} 14 \times 43$ & $\mathrm{~W} 14 \times 34$ \\
\hline 20 & $\mathrm{~W} 14 \times 43$ & $\mathrm{~W} 14 \times 34$ & $\mathrm{~W} 14 \times 22$ \\
\hline Weight (kN) & 985.75 & 959.16 & 911.78 \\
\hline Number of Analyses & 20000 & 20000 & 16000 \\
\hline
\end{tabular}

clear that more than analyses are needed for SFLA and IWO to converge while 16000 (under 200 iterations) is sufficient for the hybrid method. The minimum weight obtained by SFLA-IWO is compared to those of some other studies as well. Fig. 12 depicts the element stress ratio of the inter-story drift to the allowable inter-story drift in the optimum frame design. The SFLA-IWO algorithm found better solution vector compared to other considered hybrid algorithms. It should be noted that the best design found by hybrid method are $3.63 \%, 3.21 \%, 5.38 \%$ lighter than those of ES-DE (Talatahari et al. [33]), HBBPSO (Kaveh et al. [34]), HBB-BC (Kaveh and Talatahari [14]), respectively. Table 7 compares the optimal results of the SFLA-IWO with those of other hybrid algorithms. The ratios of the inter-story drift to the allowable inter-story drift evaluated at the best design optimized by SFLA-IWO algorithm are illustrated in Fig. 13.

\subsection{Discussion on the efficiency of the SFLA-IWO}

Solution of above examples shows that the performance of SFLA-IWO is better than the other algorithms. It is interesting to notice that although SFLA-IWO algorithm has excellent optimization performance, its CPU time is quite comparable with that of the other optimization algorithms. The key reasons for the enhancements gained by the hybridization can be summarized as follows:

a) Increasing the exploitation ability: In frame structure optimization, usually there are some local optimums in the neighborhood of a desirable solution. Thus, the probability of finding a desirable optimum increase with additional searches around the local optimums. This method does extra search (exploitation) around the local optimums and therefore gains the desirable solution with higher probability in a smaller number of iterations. Increasing the exploitation ability by hybridization, not only can enhance the results, but also reduces the standard deviation considerably.

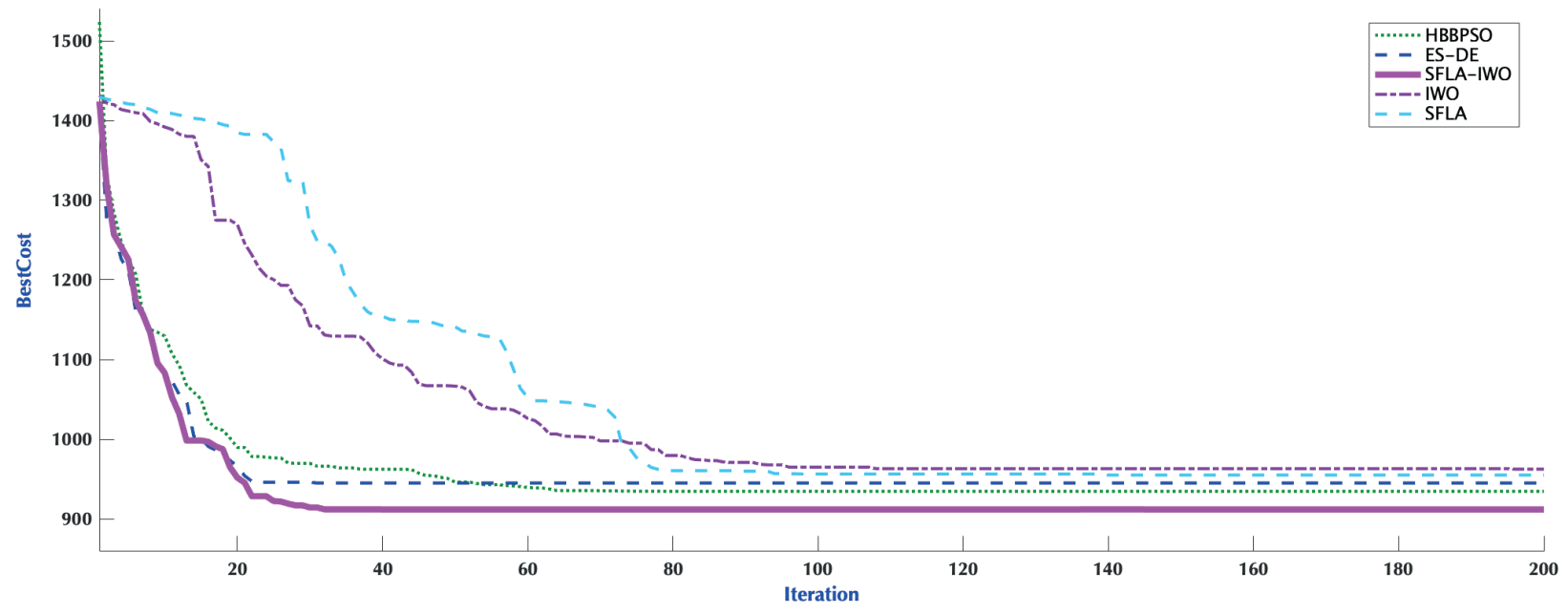

Fig. 11 Convergence of the 3-bay 24-story 
b) Improving the exploration ability: In the metaheuristic algorithms two factors are utilized consisting of the random seek factor and the data collection from the search throughout optimization process. In early iterations, the random seek factor has more power than the collective data factor, but the increase in the number of iterations step by step abates the power of the random search factor and increases the power of the collective data factor. In SFLAIWO, SFLA stage plays an auxiliary role in increasing the collective data factor; consequently, the convergence rate increases faster. SFLA-IWO needed 39 iterations to reach the best solution in 1-bay 8-story frame, while SFLA and IWO could not reach to a best solution until the maximum number of iterations has been achieved, i.e. 100 iterations [24].

\section{Conclusions}

In this study, a recently developed optimization method is utilized to find the optimal design of frame structures. The optimization algorithm, called the SFLA-IWO, has capability of finding global optima using smaller number of structural analyses. In this method, SFLA helps IWO process not only to perform the global exploration for rapidly attaining the feasible solution space but also effectively helps to reach optimal or near optimal solutions. In order to assess the robustness and effectiveness of the SFLA-IWO algorithm, some structural optimization problems are performed. It is visible that the standard deviation of the SFLA-IWO is less than that of its basic algorithms, which proves lower scattering of the SFLA-IWO solutions. Three test problems are optimized using the SFLA-IWO and its improved variants to evaluate the effectiveness, efficiency and robustness of the algorithm. The comparison of the results of this hybrid algorithm with those of other methods shows that the SFLA-IWO algorithm provides results better than other algorithms.

Table 7 Comparison of optimized 3-bay 24-story frame obtained through SFLA-IWO with other hybrid algorithms

\begin{tabular}{|c|c|c|c|c|}
\hline 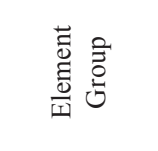 & 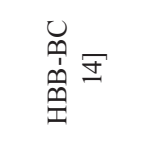 & 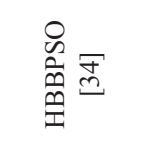 & 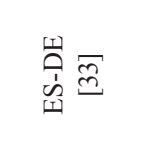 & 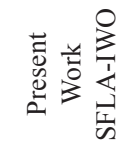 \\
\hline 1 & $\mathrm{~W} 30 \times 90$ & $\mathrm{~W} 30 \times 90$ & $\mathrm{~W} 30 \times 90$ & $\mathrm{~W} 30 \times 90$ \\
\hline 2 & $\mathrm{~W} 21 \times 48$ & $\mathrm{~W} 21 \times 55$ & $\mathrm{~W} 21 \times 55$ & $\mathrm{~W} 21 \times 48$ \\
\hline 3 & $\mathrm{~W} 18 \times 46$ & $\mathrm{~W} 21 \times 48$ & W21 $\times 48$ & W21 × 48 \\
\hline 4 & $\mathrm{~W} 8 \times 21$ & $\mathrm{~W} 8 \times 24$ & $\mathrm{~W} 10 \times 45$ & $\mathrm{~W} 12 \times 19$ \\
\hline 5 & $\mathrm{~W} 14 \times 176$ & $\mathrm{~W} 14 \times 176$ & $\mathrm{~W} 14 \times 145$ & $\mathrm{~W} 14 \times 176$ \\
\hline 6 & W14 × 159 & $\mathrm{~W} 14 \times 90$ & W14 × 109 & W14 × 109 \\
\hline 7 & W14 × 109 & W14 × 99 & W14 × 99 & W14 × 109 \\
\hline 8 & $\mathrm{~W} 14 \times 90$ & W14 × 99 & $\mathrm{~W} 14 \times 145$ & $\mathrm{~W} 14 \times 90$ \\
\hline 9 & $\mathrm{~W} 14 \times 82$ & $\mathrm{~W} 14 \times 74$ & W14 × 109 & $\mathrm{~W} 14 \times 90$ \\
\hline 10 & $\mathrm{~W} 14 \times 74$ & $\mathrm{~W} 14 \times 74$ & $\mathrm{~W} 14 \times 48$ & $\mathrm{~W} 14 \times 48$ \\
\hline 11 & $\mathrm{~W} 14 \times 38$ & $\mathrm{~W} 14 \times 38$ & $\mathrm{~W} 14 \times 38$ & $\mathrm{~W} 14 \times 30$ \\
\hline 12 & $\mathrm{~W} 14 \times 30$ & $\mathrm{~W} 14 \times 34$ & $\mathrm{~W} 14 \times 30$ & $\mathrm{~W} 14 \times 34$ \\
\hline 13 & $\mathrm{~W} 14 \times 159$ & $\mathrm{~W} 14 \times 145$ & W14 × 99 & $\mathrm{~W} 14 \times 90$ \\
\hline 14 & $\mathrm{~W} 14 \times 132$ & $\mathrm{~W} 14 \times 132$ & $\mathrm{~W} 14 \times 132$ & $\mathrm{~W} 14 \times 120$ \\
\hline 15 & W14 × 109 & W14 × 109 & W14 × 109 & W14 × 99 \\
\hline 16 & $\mathrm{~W} 14 \times 82$ & $\mathrm{~W} 14 \times 90$ & $\mathrm{~W} 14 \times 68$ & $\mathrm{~W} 14 \times 90$ \\
\hline 17 & $\mathrm{~W} 14 \times 68$ & $\mathrm{~W} 14 \times 74$ & $\mathrm{~W} 14 \times 68$ & $\mathrm{~W} 14 \times 61$ \\
\hline 18 & $\mathrm{~W} 14 \times 48$ & $\mathrm{~W} 14 \times 48$ & $\mathrm{~W} 14 \times 68$ & $\mathrm{~W} 14 \times 53$ \\
\hline 19 & $\mathrm{~W} 14 \times 34$ & $\mathrm{~W} 14 \times 38$ & $\mathrm{~W} 14 \times 61$ & $\mathrm{~W} 14 \times 34$ \\
\hline 20 & $\mathrm{~W} 14 \times 26$ & $\mathrm{~W} 14 \times 22$ & $\mathrm{~W} 14 \times 22$ & $\mathrm{~W} 14 \times 22$ \\
\hline Weight $(\mathrm{kN})$ & 960.90 & 941.55 & 944.94 & 911.78 \\
\hline
\end{tabular}

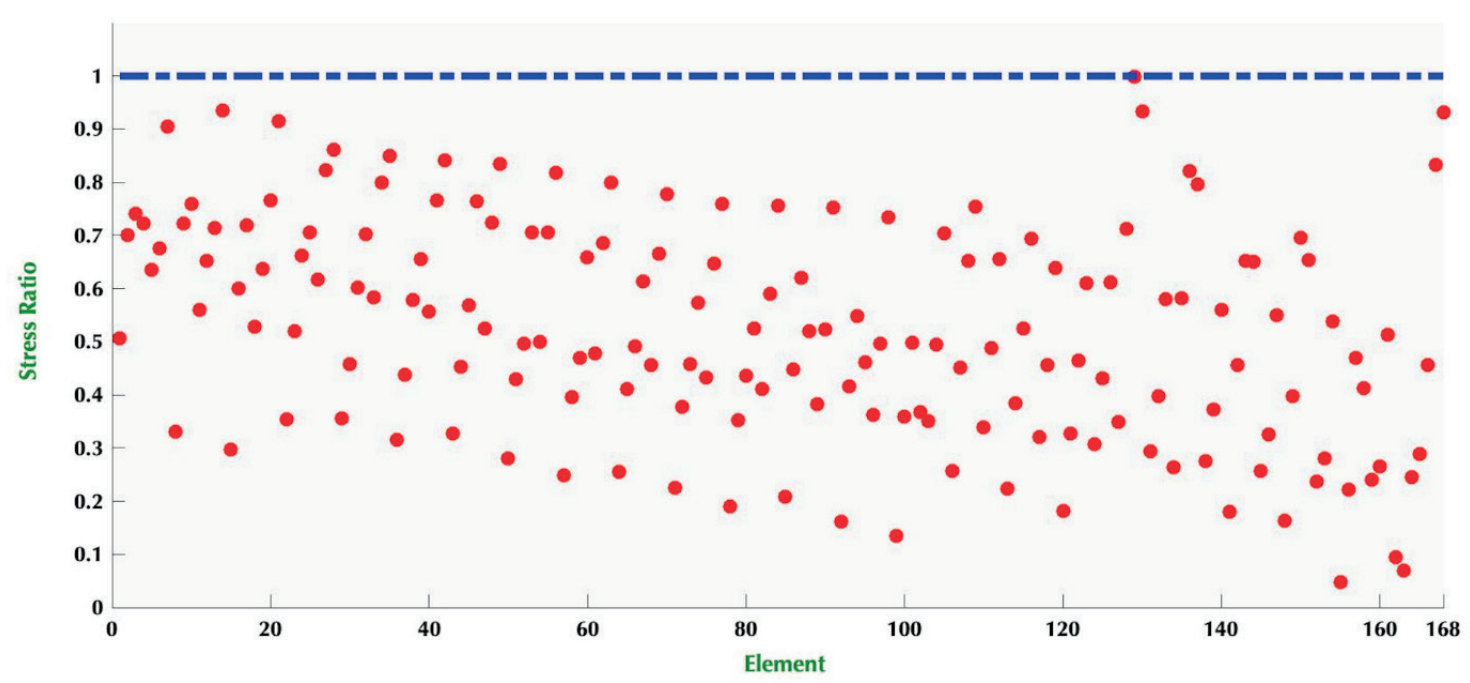

Fig. 12 The element stress ratio in the optimum frame design for the 3-bay 24-story 


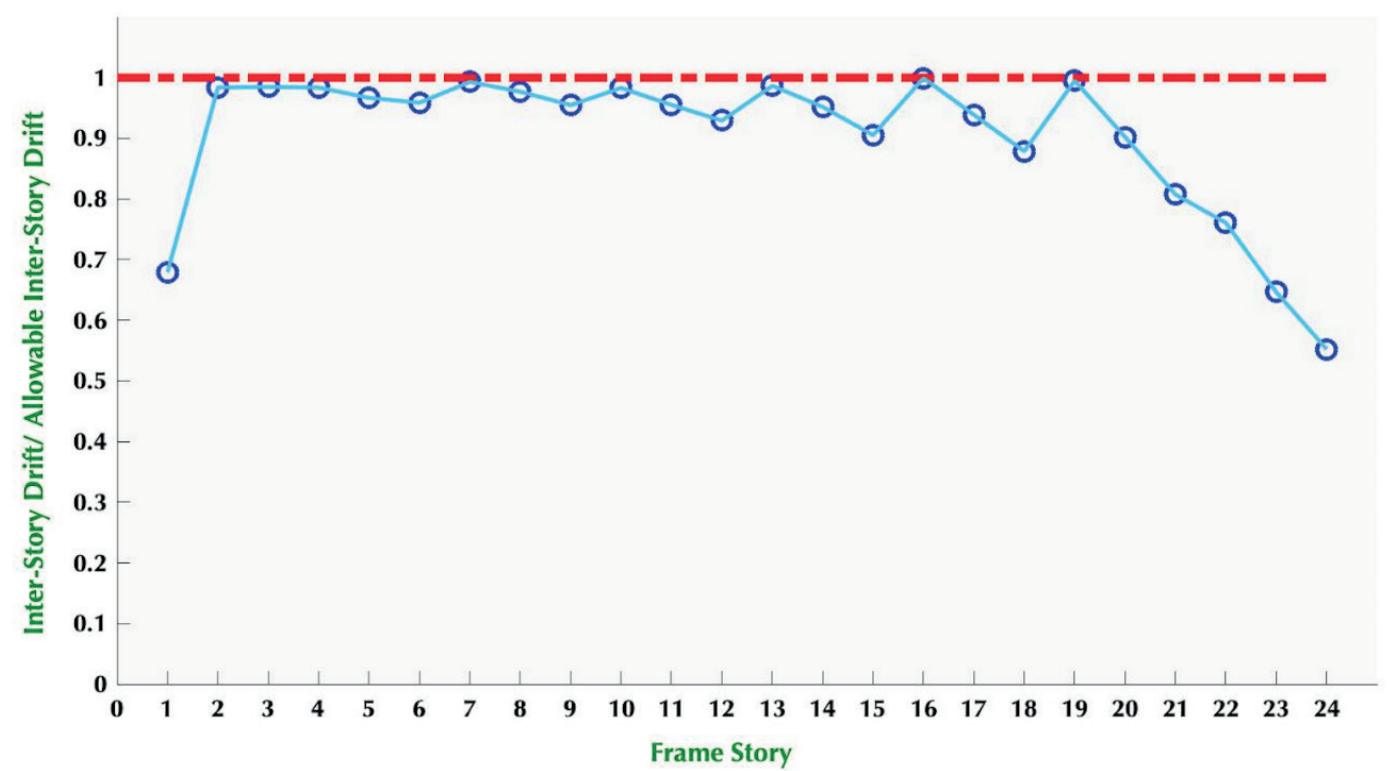

Fig. 13 The ratio of the inter-story drift to the allowable inter-story drift in the optimum frame design for the 3-bay 24-story

\section{References}

[1] Kicinger, R., Arciszewsk, T., De Jong, K. "Evolutionary computation and structural design: a survey of the state-of-the-art", Computers and Structures, 83(23-24), pp. 1943-1978, 2005.

https://doi.org/10.1016/j.compstruc.2005.03.002

[2] Kaveh, A. "Advances in Metaheuristic Algorithms for Optimal Design of Structures", 2nd ed., Springer, Cham, Switzerland, 2017. https://doi.org/10.1007/978-3-319-46173-1

[3] Kaveh, A. "Applications of Metaheuristic Optimization Algorithms in Civil Engineering", 1st ed., Springer, Cham, Switzerland, 2017. https://doi.org/10.1007/978-3-319-48012-1

[4] Goldberg, D. E., Samtani, M. P. "Engineering optimization via genetic algorithm", In: Proceedings of The 9th Conference on Electronic Computation, ASCE, New York, NY, USA, 1986, pp. 471-482.

[5] Saka, M. P. "Optimum design of steel sway frames to BS5950 using harmony search algorithm", Journal of Constructional Steel Research, 65(1), pp. 36-43, 2009.

https://doi.org/10.1016/j.jcsr.2008.02.005

[6] Kennedy, J., Eberhart, R. "Particle swarm optimization", presented at Proceedings of ICNN'95 - International Conference on Neural Networks, Perth, WA, Australia, Australia, Nov. 27-Dec. 1, 1995. https://doi.org/10.1109/ICNN.1995.488968

[7] Colorni, A., Dorigo M., Maniezzo, V. "Distributed Optimization by Ant Colony", In: Varela, F., Bourgine, P. (eds.) Proceedings of the European Conference on Artificial Life, ECAL'91, Paris, France, 1991, pp. 134-142.

[8] Kaveh, A., Talatahari, S. "Charged system search for optimal design of frame Structures", Applied Soft Computing, 12(1), pp. 382-393, 2012.

https://doi.org/10.1016/j.asoc.2011.08.034

[9] Kaveh, A., Khayatazad, M. "A novel meta-heuristic method: Ray Optimization", Computers and Structures, 112-113, pp. 238-294, 2012.

https://doi.org/10.1016/j.compstruc.2012.09.003
[10] Erol, O. K., Eksin, I. "A new optimization method: Big Bang-Big Crunch", Advances in Engineering Software, 37(2), pp. 106-111, 2006.

https://doi.org/10.1016/j.advengsoft.2005.04.005

[11] Kaveh, A., Bakhshpoori, T. "A new metaheuristic for continuous structural optimization: water evaporation optimization", Structural and Multidisciplinary Optimization , 54(1), pp. 23-43, 2016. https://doi.org/10.1007/s00158-015-1396-8

[12] Camp, C. V. "Design of Space Trusses Using Big Bang-Big Crunch Optimization", Journal of Structural Engineering, 133(7), pp. 9991008, 2007.

https://doi.org/10.1061/(ASCE)0733-9445(2007)133:7(999)

[13] Kaveh, A., Abbasgholiha, H. "Optimum design of steel sway frames using Big Bang-Big Crunch algorithm", Asian Journal of Civil Engineering, 12(3), pp. 293-317, 2011. https://doi.org/10.13140/RG.2.1.3477.4480

[14] Kaveh, A., Talatahari, S. "A discrete Big Bang - Big Crunch algorithm for optimal design of skeletal structures", Asian Journal of Civil Engineering, 11(1), pp. 103-122, 2010.

[15] Tejani, G. G., Bhensdadia, V. H., Bureerat, S. "Examination of three meta-heuristic algorithms for optimal design of planar steel frames", Advances in Computational Design, 1(1), pp. 79-86, 2016. https://doi.org/10.12989/acd.2016.1.1.079

[16] Bhensdadia, V., Tejani, G. G. "Grey Wolf Optimizer (GWO) Algorithm for Minimum Weight Planer Frame Design Subjected to AISC-LRFD", In: Satapathy, S. C., Joshi, A., Modi, N., Pathak, N. (eds.) Proceedings of 4th International Conference on ICT for Sustainable Development, Amsterdam, The Netherlands, 2016, pp. 143-151.

https://doi.org/10.1007/978-981-10-0135-2_13

[17] Kazemzadeh Azad, S., Hasançebi, O., Erol, O. K. "Evaluating efficiency of big bang- big crunch algorithm in benchmark engineering optimization problems", International Journal of Optimization in Civil Engineering, 1(3), pp. 495-505, 2011. 
[18] Kazemzadeh Azad, S., Hasançebi, O., Kazemzadeh Azad, S. "Upper bound strategy for metaheuristic based design optimization of steel frames", Advances in Engineering Software, 57, pp. 19-32, 2013. https://doi.org/10.1016/j.advengsoft.2012.11.016

[19] Kaveh, A., Malakouti Rad, S. "Hybrid genetic algorithm and particle swarm optimization for the force method-based simultaneous analysis and design", Iranian Journal of Science and Technology, 34(B1), pp. 15-34, 2010.

[20] Juang, C.-F. "A hybrid of genetic algorithm and particle swarm optimization for recurrent network design", IEEE Transactions on Systems, Man, and Cybernetics, 34(2), pp. 997-1006, 2004. https://doi.org/10.1109/TSMCB.2003.818557

[21] Kaveh, A., Talatahari, S. "Hybrid Algorithm of Harmony Search, Particle Swarm and Ant Colony for Structural Design Optimization", In: Geem, Z. W. (ed.) Harmony Search Algorithms for Structural Design Optimization, 1st ed., Springer, Berlin, Germany, 2009. pp. 159-198. https://doi.org/10.1007/978-3-642-03450-3_5

[22] Eusuff, M., Lansey, K., Pasha, F. "Shuffled frog-leaping algorithm: a memetic meta-heuristic for discrete optimization", Engineering Optimization, 38(2), pp. 129-154, 2006. https://doi.org/10.1080/03052150500384759

[23] Mehrabian, A. R, Lucas, C. "A novel numerical optimization algorithm inspired from weed colonization", Ecological Informatics, 1(4), pp. 355-366, 2006. https://doi.org/10.1016/j.ecoinf.2006.07.003

[24] Kaveh, A., Talatahari, S., Khodadadi, N. "Hybrid Invasive Weed Optimization-Shuffled Frog-Leaping Algorithm for Optimal Design of Truss Structures", Iranian Journal of Science and Technology, Transactions of Civil Engineering, 2019. https://oi.org/10.1007/s40996-019-00280-0

[25] AISC Manual Committee "Manual of Steel Construction - Load Resistance Factor Design", 3rd ed., American Institute of Steel Construction, Chicago, IL, USA, 2001.
[26] Kaveh, A., Farhmand Azar. B., Talatahari, S. "Ant Colony Optimization for Design of Space Trusses", International Journal of Space Structures, 23(3), pp. 167-181, 2008. https://oi.org/10.1260/026635108786260956

[27] McGuire, W. "Steel structures", 2nd ed., Prentice Hall, Upper Saddle River, NJ, USA, 1968.

[28] Nguyen, H. D. "A Hybrid SFL-Bees Algorithm", International Journal of Computer Applications, 128(5), pp. 13-18, 2015. https://doi.org/10.5120/ijca2015906541

[29] Huynh, T.-H. "A modified shuffled frog leaping algorithm for optimal tuning of multivariable PID controllers", In: 2008 IEEE International Conference on Industrial Technology, Chengdu, China, 2008, pp. 1-6. https://doi.org/10.1109/ICIT.2008.4608439

[30] Kaveh, A., Talatahari, S. "A discrete particle swarm ant colony optimization for design of steel frames", Asian Journal of Civil Engineering, 9(6), pp. 563-575, 2007.

[31] Khajeh, A., Ghasemi, M. R., Ghohani Arab, H. "Hybrid particle swarm optimization, grid search method and univariate method to optimally design steel frame structures", International Journal of Optimization in Civil Engineering, 7(2), pp. 171-189, 2017. [online] Available at: http:/ijoce.iust.ac.ir/browse.php?a id=292\&sid=1\&slc_lang=en [Accessed: 20 June 2019]

[32] Kaveh, A., Hoseini Vaez, S. R., Hosseini, P. "Modified Dolphin Monitoring Operator for Weight Optimization of Frame Structures", Periodica Polytechnica Civil Engineering, 61(4), pp. 770-779, 2017. https://doi.org/10.3311/PPci.9691

[33] Talatahari, S., Ghandomi, A. H., Yang, X.-S., Deb, S. "Optimum design of frame structures using the Eagle Strategy with Differential Evolution", Engineering Structures, 91, pp. 16-25, 2015. https://doi.org/10.1016/j.engstruct.2015.02.026

[34] Kaveh, A., Talatahari, S., Alami, M. T. "A new hybrid meta-heuristic for optimum design of frame structures", Asian Journal of Civil Engineering, 13(6), pp. 705-717, 2012. 